\title{
Recreating the Tumor Microenvironment in a Bilayer, Hyaluronic Acid Hydrogel Construct for the Growth of Prostate Cancer Spheroids
}

\author{
Xian $\mathrm{Xu}^{1,2}$, Lisa A. Gurski ${ }^{2,3}$, Chu Zhang ${ }^{2,3, \$}$, Daniel A. Harrington ${ }^{4}$, Mary C. Farach- \\ Carson $^{2,3,4}$, and Xinqiao Jia ${ }^{1,2,5,{ }^{*}}$ \\ ${ }^{1}$ Department of Materials Science and Engineering, Delaware Biotechnology Institute, University \\ of Delaware, Newark, DE 19716, USA \\ ${ }^{2}$ Center for Translational Cancer Research, University of Delaware, Newark, DE 19716, USA \\ ${ }^{3}$ Department of Biological Sciences, University of Delaware, Newark, DE 19716, USA \\ ${ }^{4}$ Departments of Biochemistry and Cell Biology and Bioengineering, Rice University, Houston, TX \\ 77251, USA \\ ${ }^{5}$ Biomedical Engineering Program, University of Delaware, Newark, DE 19716, USA
}

\begin{abstract}
Cancer cells cultured in physiologically relevant, three-dimensional (3D) matrices can recapture many essential features of native tumor tissues. In this study, a hyaluronic acid (HA)-based bilayer hydrogel system that not only supports the tumoroid formation from LNCaP prostate cancer $(\mathrm{PCa})$ cells, but also simulates their reciprocal interactions with the tumor-associated stroma was developed and characterized. HA hydrogels were prepared by mixing solutions of HA precursors functionalized with acrylate groups (HA-AC) and reactive thiols (HA-SH) under physiological conditions. The resultant viscoelastic gels have an average elastic modulus of $234 \pm 30 \mathrm{~Pa}$ and can be degraded readily by hyaluronidase. The orthogonal and cytocompatible nature of the crosslinking chemistry permits facile incorporation of cytokine-releasing particles and PCa cells. In our bilayer hydrogel construct, the top layer contains heparin (HP)-decorated, HA-based hydrogel particles (HGPs) capable of releasing heparin-binding epidermal growth factor-like growth factor (HB-EGF) in a sustained manner at a rate of $2.5 \mathrm{wt} \% /$ day cumulatively. LNCaP cells embedded in the bottom layer receive the growth factor signals from the top, and in response form enlarging tumoroids with an average diameter of $85 \mu \mathrm{m}$ by day 7. Cells in 3D hydrogels assemble into spherical tumoroids, form close cellular contacts through E-cadherin, and show cortical organization of F-actin, whereas those plated as 2D monolayers adopt a spread-out morphology. Compared to cells cultured on 2D, the engineered tumoroids significantly increased the expression of two pro-angiogenic factors, vascular endothelial growth factor-165 $\left(\mathrm{VEGF}_{165}\right)$ and interleukin-8 (IL-8), both at mRNA and protein levels. Overall, the HA model system provides a
\end{abstract}

\footnotetext{
(C) 2012 Elsevier Ltd. All rights reserved.

*To whom correspondence should be addressed: Xinqiao Jia, 201 DuPont Hall, Department of Materials Science and Engineering, University of Delaware, Newark, DE, 19716, USA. Phone: 302-831-6553, Fax: 302-831-4545, xjia@udel.edu..

\$Current Address: Department of Molecular and Cell Biology, University of Connecticut 354 Mansfield Road, Unit 2131, Storrs, CT 06269, USA

Publisher's Disclaimer: This is a PDF file of an unedited manuscript that has been accepted for publication. As a service to our customers we are providing this early version of the manuscript. The manuscript will undergo copyediting, typesetting, and review of the resulting proof before it is published in its final citable form. Please note that during the production process errors may be discovered which could affect the content, and all legal disclaimers that apply to the journal pertain.
} 
useful platform for the study of tumor cell responses to growth factors and for screening of anticancer drugs targeting these pathways.

\section{Keywords}

Hyaluronic Acid; Hydrogels; 3D Tumor Model; Growth Factor; Prostate Cancer; Tumoroid

\section{Introduction}

For decades, cancer biologists relied on two-dimensional (2D) monolayer cell culture platforms and/or in vivo animal models (xenografts) to investigate the complex mechanisms of tumorigenesis, angiogenesis, invasion and metastasis [1,2]. Using these complementary systems, researchers have gained improved understanding of cancer biology and have developed many efficacious anti-cancer treatment methods. However, both monolayer cultures and xenografts have inherent limitations [3]. Because of the lack of spatial guidance cues needed to establish proper cell-cell contacts and cell-matrix interactions, 2D cell cultures are physiologically irrelevant and experimentally unreliable [4-6]. Although studies based on animal models predict more pathologically relevant outcomes, the presence of many uncontrollable variables associated with these models makes it challenging to determine the impact of specific factors on tumor progression or to identify the therapeutic efficacies of novel personalized medicine [3]. Moreover, testing therapeutic agents in animal xenografts is expensive, tedious and time consuming, thus further delaying the translation of new technologies from bench to bedside [4].

Recently, various three-dimensional (3D) cell culture systems have been developed as alternative in vitro platforms for improved understanding of cancer biology [1, 2, 5-9]. These 3D culture systems have the potential to overcome the limitations associated with traditional 2D monolayer cultures, as well as the complexities of in vivo models, by generating a tightly controlled molecular and mechanical microenvironment typical of tumors in vivo [6]. Both natural (e.g. basement membrane extract [10, 11], type I collagen $[3,7,12]$ ) and synthetic materials (e.g. PLGA [6] and PEG [5, 13]) have been used to create matrices and scaffolds for tumor engineering purposes. For instance, researchers have cultured breast cancer cells in Matrigel ${ }^{\mathrm{TM}}$ to investigate the relationship between colony morphology and gene expression [14]. In other studies, medical grade poly( $\varepsilon$-caprolactone)tricalcium phosphate composite scaffolds were used to study prostate cancer (PCa) bone metastasis [15]. In general, hydrogels derived from animal tissues suffer from batch-to-batch variations [5], whereas those prepared using synthetic polymers are physiologically irrelevant [16]; therefore these materials have limited applications in in vitro tumor engineering.

We are interested in the in vitro reconstruction of prostate tumor tissues using hyaluronic acid (HA)-based hydrogels [17]. HA is a ubiquitous non-sulfated glycosaminoglycan (GAG) present in extracellular matrices (ECM) of all vertebrates [18]. HA is not only a structural component in the tumor ECM that contributes to the overall tissue integrity but also a biologically active molecule that promotes tumor progression through cell signaling. Expressed by both motile PCa epithelial cells and associated stromal cells, HA is concentrated within the tumor-associated stromal ECM $[19,20]$. The entangled, HA-rich matrix can be partially degraded by hyaluronidase (HAase), thereby creating a permissive pathway for the migration of tumor cells [21]. The migration process is mediated by cell surface HA receptors such as CD44 or RHAMM [19]. HA also protects the tumor tissues against immune surveillance and chemotherapeutic agents [19,22]. Finally, the angiogenic properties of HA fragments [23] facilitate the recruitment of new blood vessels into the 
growing tumor. Therefore, HA-based hydrogels have been used for in vitro culture of poorly adherent bone metastatic PCa cells (C4-2B) [17] and in studies of the mechanobiology of malignant brain tumors [8].

Increasing evidence points to the active roles cancer-associated stroma plays in tumor initiation and progression [24]. The crosstalk between the tumor tissue and its surrounding stroma relies on the biological paracrine signaling mediated by soluble factors secreted by cancer cells or neighboring stromal cells. These secreted factors direct the remodeling of the stromal microenvironment and the progression of the disease [25-27], thus profoundly affecting the growth, invasion and metastasis of tumor tissues [26]. Although various in vitro tumor models have been created using 3D matrices, the stromal component often has been overlooked. Our studies were designed to address the need to establish 3D culture systems that can recreate the unique tumor-stroma niche. In particular, we sought to introduce the controlled release of ECM bound factors to allow for the in vitro engineering of tumor tissues under well-controlled and reproducible conditions that are amenable to clinical testing. Among the various biological cues involved in prostate tumor-stromal interactions, heparin-binding epidermal growth factor-like growth factor (HB-EGF) is widely recognized as a crucial mediator for tumorigenesis and cancer progression [28]. HBEGF is secreted by a variety of stromal cells, such as fibroblasts [27] and associated inflammatory cells [29], and is mainly localized in smooth muscle compartments within the prostate stroma [28]. HB-EGF serves as a strong mitogen for tumor growth [27, 30] and is a potent inducer of angiogenesis [30].

We describe herein a bilayer hydrogel platform that was created using orthogonally functionalized HA derivatives as the building blocks and HA-based hydrogel particles (HGPs) [31] as HB-EGF-releasing devices. To mimic the tumor/stroma interaction, HBEGF-loaded HGPs were entrapped within the top gel layer while LNCaP PCa cells were encapsulated in the bottom layer (Figure 1A). The mechanical properties and enzymatic degradation of the hydrogel matrix were evaluated by rheometric and colorimetric analyses, respectively. The HB-EGF release kinetics were quantified by ELISA. The cytocompatibility of the hydrogel matrix was confirmed both by live/dead staining and PicoGreen assay. Cell adhesion and cell morphology were characterized by standard immunohistochemical analyses. The expression and production of angiogenic factors were quantified at both the mRNA level and the protein level. Overall, the HA-based bilayer platform supports the growth of prostate tumoroids, models paracrine interactions in the tumor microenvironment, and leads to the production of pro- angiogenic signals in growing tumoroids.

\section{Materials and Methods}

\subsection{Materials}

HA (sodium salt) was generously donated by Genzyme Corporation (500 kDa, Cambridge, MA) or purchased from Lifecore Biomedical (357 kDa, Chaska, MN). 3,3'-Dithiobis (propanoic acid), hydrazine hydrate, 1-ethyl-3-(3-(dimethylamino)propyl) carbodiimide (EDC), 1-hydroxybenzotriazole (HOBt), dithiothreitol (DTT), adipic acid dihydrazide (ADH), N-acryloxysuccinimide (NHS-AC), heparin (HP, sodium salt, $18 \mathrm{KDa}, 177$ USP units $\mathrm{mg}^{-1}$ ) from porcine intestinal mucosa, dioctyl sulfosuccinate sodium salt (AOT, 98\%), 2,2,4-trimethylpentane (isooctane, anhydrous), divinyl sulfone (DVS) and bovine testicular hyaluronidase (HAase, 30,000 U/mg) were obtained from Sigma Aldrich (Milwaukee, WI). Cascade blue hydrazide (CB, sodium salt) was purchased from Molecular Probes (Carlsbad, CA). Recombinant human HB-EGF and the Quantikine ELISA kits for vascular endothelial growth factor-165 $\left(\mathrm{VEGF}_{165}\right)$ and interleukin-8 (IL-8) were purchased from R\&D Systems (Minneapolis, MN). The ELISA kit for HB-EGF was purchased from RayBiotech, Inc. 
(Norcross, GA). Alexa Fluor® 488 Mouse anti-human E-Cadherin was obtained from BD Pharmingen TM (San Diego, CA). LNCaP PCa cells were obtained from American Type Culture Collection (ATCC, Manassas, VA). NuPAGE® Bis-Tris Gel was purchased from Life Technologies (Grand Island, NY). Rabbit anti-HYAL1 antibody and primary and secondary antibodies for $\beta$-actin were purchased from Sigma (Milwaukee, WI). Goat antirabbit HRP-conjugated secondary antibody was obtained from Thermo Fisher Scientific (Barrington, IL). All cell culture reagents were purchased from Invitrogen (Carlsbad, CA). All other reagents were used as received unless otherwise noted.

\subsection{Cell culture}

LNCaP PCa cells were maintained in Corning (Lowell, MA) tissue culture flasks $\left(75 \mathrm{~cm}^{2}\right.$ ) at $37{ }^{\circ} \mathrm{C}$ in $5 \%(\mathrm{v} / \mathrm{v}) \mathrm{CO}_{2}$ in a RPMI-1640 medium supplemented with $5 \%(\mathrm{v} / \mathrm{v})$ fetal bovine serum (FBS), $100 \mathrm{U} / \mathrm{mL}$ penicillin G sodium and $100 \mu \mathrm{g} / \mathrm{mL}$ streptomycin sulfate in $0.085 \%$ $(\mathrm{v} / \mathrm{v})$ saline $(\mathrm{P} / \mathrm{S})$. The medium was changed every other day, and cells were routinely passaged using $0.25 \%(\mathrm{w} / \mathrm{v})$ trypsin containing ethylenediaminetetraacetic acid (EDTA.4Na).

\subsection{Synthesis and characterization of soluble HA precursors}

HA with a molecular weight of $500 \mathrm{KDa}$ was used for the synthesis of HA derivatives. Acrylated HA (HA-AC) was synthesized by reacting adipic acid dihydrazide-modified HA (HA-ADH, 35\% ADH incorporation determined by ${ }^{1} \mathrm{H}$ NMR [18]) with $\mathrm{N}$ acryloxysuccinimide (NHS-AC), as previously reported [32]. The product was obtained as a freeze-dried solid (yield: 70\%). Sulfhydryl groups were incorporated in HA (HA-SH) via the reaction with a disulfide-containing dihydrazide compound, followed by reduction with DTT, according to reported methods [33]. The solid HA-SH was obtained after lyophilization (yield: $80 \%$ ). The chemically modified HA products, HA-AC and HA-SH, were stored at $-20{ }^{\circ} \mathrm{C}$ prior to use. The degree of modification and the molecular weight of HA derivatives were characterized by ${ }^{1} \mathrm{H}$ NMR and gel permeation chromatography (GPC), respectively.

\subsection{Synthesis and characterization of HA hydrogels}

2.4.1 Hydrogel synthesis-HA derivatives were separately dissolved in phosphate buffered saline (PBS, pH 7.4) at a concentration of $20 \mathrm{mg} / \mathrm{mL}$. After the HA-AC and HASH solutions were thoroughly mixed $(1 / 1, \mathrm{v} / \mathrm{v})$, the mixture was aliquoted to cell culture inserts (Diameter: $12 \mathrm{~mm}$, pore size: $0.4 \mu \mathrm{m}$ ) and were incubated at $37{ }^{\circ} \mathrm{C}$ for $6 \mathrm{~h}$ to obtain fully crosslinked hydrogel discs (height: $1.3 \mathrm{~mm}$, diameter: $12 \mathrm{~mm}$ ).

2.4.2 Oscillatory rheology-The rheological properties of the HA hydrogels were evaluated using a controlled stress rheometer (AR-G2, TA Instruments, New Castle, DE) with a parallel plate geometry (20 $\mathrm{mm}$ diameter). Immediately after mixing, the precursor mixture was loaded on the geometry, and mineral oil then was applied around the sample to prevent water evaporation during the measurement. The linear viscoelastic region was determined by a strain sweep from 0.1 to $1000 \%$ at an angular frequency of $6 \mathrm{rad} / \mathrm{s}$. A time sweep experiment was conducted for $6 \mathrm{~h}$ at a frequency of $6 \mathrm{rad} / \mathrm{s}$ and a strain of $1 \%$. A frequency sweep experiment within the linear viscoelastic range was performed after the time sweep measurement at $1 \%$ strain from 0.1 to $100 \mathrm{rad} / \mathrm{s}$. Samples were tested at $37{ }^{\circ} \mathrm{C}$ with a gap size of $100 \mu \mathrm{m}$. All measurements were conducted in triplicate.

2.4.3 Swelling ratio and sol fraction-The as-synthesized hydrogels were allowed to swell in PBS at $37^{\circ} \mathrm{C}$ for $24 \mathrm{~h}$. After a thorough wash with DI water, samples were dehydrated by passing through graded ethanol solutions. After drying at $37^{\circ} \mathrm{C}$ overnight, the 
hydrogel dry weight was recorded. The sol faction was calculated based on the ratio of the final dry weight of the hydrogel to the initial solid mass used in the gel preparation.

Separately, previously dried gel discs were re-immersed in PBS at $37{ }^{\circ} \mathrm{C}$ for $24 \mathrm{~h}$ and the wet weight was recorded. The swelling ratio was determined as the ratio of the final wet weight to the measured dry weight. The measurements were performed in triplicate.

2.4.4 Degradation-A total of three groups of hydrogel discs (triplicate samples for each group) were allowed to swell in PBS at $37{ }^{\circ} \mathrm{C}$ for $24 \mathrm{~h}$. The average dry weight $\left(\mathrm{W}_{1}\right)$ of one group of hydrogel discs was measured as described above. Then, the stability of the other two groups of hydrogel samples was evaluated by immersing the discs in PBS with or without HAase $(5 \mathrm{U} / \mathrm{mL})$. The degradation solution collected every other day was stored at $-20{ }^{\circ} \mathrm{C}$ until further analysis. The degradation medium was replenished with PBS or a freshly prepared enzyme solution. The amount of HA degraded $\left(\mathrm{W}_{2}\right)$ at each time point was quantified using the carbazole assay following a reported procedure [34]. The weight fraction of the remaining hydrogels (wt \%) at each time point was calculated using the equation: $\mathrm{wt} \%=\frac{\mathrm{w}_{1}-\mathrm{w}_{2}}{\mathrm{w}_{1}} \times 100 \%$.

\subsection{Synthesis and characterization of hydrogel particles (HGPs)}

HP-decorated, HA-based HGPs (HA/HP HGPs) were synthesized using an inverse emulsion crosslinking process, as previously described [31]. The amount of HP covalently incorporated in the HGPs was $0.6 \mu \mathrm{g} / \mathrm{mg}$, and the particles had an average diameter of 1.1 $\mu \mathrm{m}$ [31]. To label HGPs fluorescently, $5 \mathrm{mg} \mathrm{HA} / \mathrm{HP}$ HGPs were dispersed in $1 \mathrm{~mL}$ DI water containing $0.54 \mathrm{mg} / \mathrm{mL}$ sodium periodate. The reaction was allowed to proceed in the dark overnight under constant agitation, followed by thorough washing with DI water. The oxidized HGPs bearing aldehyde groups then were allowed to react with cascade blue hydrazide $(7.45 \mathrm{mg})$ in $1 \mathrm{~mL}$ DI water for $6 \mathrm{~h}$ in the dark. The resulting fluorescent particles were subjected to exhaustive washing with DI water, ethanol and acetone before being dried at room temperature.

\subsection{HB-EGF loading and release}

HB-EGF loading and release were measured according to reported procedures [31, 35]. Briefly, one mg HGPs were incubated with $200 \mathrm{ng}$ of HB-EGF in $200 \mu \mathrm{L}$ of binding buffer (0.1 wt $\%$ BSA) for $2 \mathrm{~h}$ at ambient temperature. The supernatant containing unloaded HBEGF then was collected by centrifugation $(14,000 \mathrm{rpm}, 5 \mathrm{~min})$ and stored at $-20^{\circ} \mathrm{C}$ for further quantification. HGP-embedded hydrogels were prepared following the procedure described above for the bulk gels, except that $1 \mathrm{mg}$ of HB-EGF-loaded HGPs were thoroughly mixed with hydrogel precursors prior to gelation. To quantify HB-EGF release in vitro, particles or hydrogel discs were incubated in the release medium (RPMI-1640) at 37 ${ }^{\circ} \mathrm{C}$. At a predetermined time, the supernatant was collected and the releasing medium was replenished with fresh medium of equal volume. The HB-EGF concentration in the supernatant was quantified by using the ELISA kit. The encapsulation efficiency (EE) was calculated by dividing the amount of HB-EGF loaded into the particles by the amount of HB-EGF initially added. The loading content (LC) was defined as the amount of HB-EGF (ng) loaded per mg HGPs. The cumulative release was calculated as the total amount of HBEGF released at a particular time point relative to the amount initially loaded.

\subsection{Cell culture in bilayer HA hydrogels}

Cell culture inserts were pre-wet with PBS before being placed into a 24-well culture plate (Beckton-Dickenson Labware, Franklin Lakes, NJ). To prepare the cell-containing bottom gel layer (Figure 1B), HA-SH $(100 \mu \mathrm{L}, 20 \mathrm{mg} / \mathrm{mL})$ was added to the HA-AC solution (100 $\mu \mathrm{L}, 20 \mathrm{mg} / \mathrm{mL})$ containing dispersed LNCaP cells $\left(2 \times 10^{5}\right)$. After thorough mixing, the cell 
suspension was transferred into the cell culture insert and was incubated for $45 \mathrm{~min}$ at $37^{\circ} \mathrm{C}$ before the medium was added around the insert. HGP-embedded hydrogel (Figure 1B) was prepared as stated above, with $5 \mathrm{mg}$ HB-EGF-loaded HGPs being encapsulated within the hydrogel discs. The bilayer construct was assembled by overlaying the HGP-containing hydrogel on top of the cell-laden hydrogel (Figure 1A, referred as "3D-HB-EGF"). Three dimensional cultures without the HB-EGF-releasing top layer (referred as "3D-CT") served as the controls. Two dimensional studies in which LNCaP cells were cultured on a 24-well plate at an initial cell seeding density of $1 \times 10^{4}$ cells $/ \mathrm{cm}^{2}$, with or without HB-EGF (25 ng/ $\mathrm{mL}$ ), were conducted and the respective samples were referred to as "2D-HB-EGF" and "2D-CT". The cell culture medium was changed every day for each culture.

\subsection{Characterization of tumoroids}

2.8.1 Cell viability-For 2D monolayer cultures, cells at an initial seeding density of $1 \times 10^{4}$ cells $/ \mathrm{cm}^{2}$ were plated onto an 8 -well chambered cover glass that is useful for all imaging purposes. Upon completion of the 3D culture, the bilayer construct was separated, and the bottom layer containing entrapped tumoroids was removed from the insert and placed on the cover glass. For live/dead staining, SYTO-13 and propidium iodide (PI) were diluted at 1:1000 and 1:2000 (v/v) respectively in PBS. Five hundred microliters of the staining mixture then were applied to the 2D monolayer or 3D constructs, and samples were incubated at room temperature for $20 \mathrm{~min}$. Images were acquired using a Zeiss510 NLO confocal microscope (Carl Zeiss, Maple Grove, MN). The hydrogel top layer containing cascade blue labeled HGPs was imaged separately using a Zeiss 5 LIVE DUO confocal microscope (Carl Zeiss, Maple Grove, MN).

2.8.2 Cell morphology and cell-cell adhesion-After the 2D cultures and the 3D constructs were washed thoroughly with PBS, cells were fixed in a paraformaldehyde (PFA) solution (4\% (v/v) in PBS) for $30 \mathrm{~min}$. After extensive washing, samples were immersed in Triton X-100 (0.2\% (v/v) in PBS) for $15 \mathrm{~min}$. The Triton solution was removed and samples were washed again with PBS. Samples then were treated with bovine serum albumin (BSA, $3 \mathrm{wt} \%$ in PBS) at $4{ }^{\circ} \mathrm{C}$ overnight. Subsequently, samples were incubated with 1:1000 (v/v) AlexaFluor ${ }^{\circledR} 488$ phalloidin or 1:10 AlexaFluor ${ }^{\circledR} 488$ Mouse anti-E-cadherin in $3 \mathrm{wt} \%$ BSA at $37^{\circ} \mathrm{C}$ for $3 \mathrm{~h}$ before being exposed to a 1:1000 (v/v) solution of Draq5 in $3 \mathrm{wt} \%$ BSA for another $15 \mathrm{~min}$ at room temperature. After a final wash with PBS, samples were imaged using the Zeiss510 NLO confocal microscope.

2.8.3 Cell proliferation- $\mathrm{LNCaP}$ cells were cultured on $2 \mathrm{D}$ or in $3 \mathrm{D}$, as described above. At predetermined time points, cells on 2D plastic surfaces were trypsinized and collected. Cells cultured in HA hydrogels were harvested by degrading the matrices using HAase (5 $\mathrm{KU} / \mathrm{mL}$ ) at $37^{\circ} \mathrm{C}$ for $4 \mathrm{~h}$. Cells collected from $2 \mathrm{D}$ or $3 \mathrm{D}$ cultures then were digested with a phosphate buffer ( $5 \mathrm{mM}$ L-cysteine, $5 \mathrm{mM}$ EDTA, pH 6.4) containing $125 \mu \mathrm{g} / \mathrm{mL}$ papain at $60{ }^{\circ} \mathrm{C}$ for $18 \mathrm{~h}$. The total DNA content then was quantified using a PicoGreen DNA assay (Invitrogen, Grand Island, NY) following the manufacturer's protocol.

2.8.4 Western blotting-Cells cultured under various conditions were collected as described above after 7 days of culture. Cells were lysed using a radioimmunoprecipitation (RIPA) buffer ( $50 \mathrm{mM}$ tris buffer $\mathrm{pH}=8.0,150 \mathrm{mM} \mathrm{NaCl}, 0.5 \mathrm{wt} \%$ deoxycholic acid, $1 \%$ (v/ v) Nonidet P-40, $0.1 \mathrm{wt} \%$ SDS, $200 \mu \mathrm{L} \mathrm{DI} \mathrm{H}_{2} \mathrm{O}$ ) containing a protease inhibitor cocktail

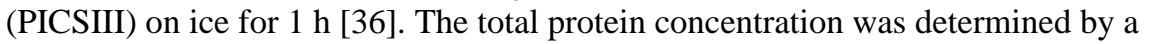
bicinchoninic acid assay (BCA) following the manufacturer's instructions. Protein samples ( $45 \mu \mathrm{g}$ each) were mixed with the sample buffer (Laemmli sample buffer supplemented with $5 \%(\mathrm{v} / \mathrm{v}) \beta$-mercaptoethanol) in equal volume and were boiled for $5 \mathrm{~min}$ before loading in the gel. Samples were electrophoresed at $95 \mathrm{~V}$ for $120 \mathrm{~min}$. Proteins then were transferred to 
a nitrocellulose membrane at $22 \mathrm{~V}$ for $90 \mathrm{~min}$. Membranes were immersed in a blocking buffer (3 wt \% BSA in PBS-1\% (v/v) Tween-20) for $1 \mathrm{~h}$. For the immunodetection of HYAL-1, a primary antibody was used at a 1:500 dilution in $3 \mathrm{wt} \%$ BSA. Goat anti-rabbit HRP-conjugated secondary antibody was applied at a 1:5000 dilution in $3 \mathrm{wt} \%$ BSA. Primary and secondary antibodies for the loading control ( $\beta$-actin) were used as 1:5000 and 1:15000 dilutions from stock in $3 \mathrm{wt} \% \mathrm{BSA}$, respectively. An enhanced chemoluminescence (ECL) reagent was used to visualize the antibody binding.

2.8.5 Evaluation of the angiogenic potential $-\mathrm{LNCaP}$ cells were collected at various time points as described above. RNA extraction, reverse transcription and quantitative polymerase chain reaction (qPCR) analysis using an ABI Prism 7300 Sequence Detection System (AB Applied Biosystems, Foster City, CA) were performed as described previously [31]. Primer sequences for specific genes were as follows: $\mathrm{VEGF}_{165}$ (NM_001171629.1): forward (5'-GAC AAG AAA ATC CCT GTG GGC-3'), reverse (5'-AAC GCG AGT CTG TGT TTT TGC-3'); IL-8 (NM_000584.3): forward (5'-CTC CAT AAG GCA CAA ACT TTC AG-3'), reverse (5'-GTC CAC TCT CAA TCA CTC TCA G-3') and $\beta$-actin (NM_001101.3, the housekeeping gene): forward (5'-GGA CTT CGA GCA AGA GAT GG-3'), reverse (5'-AGC ACT GTG TTG GCG TAC AG-3'). The relative gene expression was calculated using Equation (1) [31]:

$$
\text { ratio }=\frac{\mathrm{E}_{\text {target }} \Delta \mathrm{Ct}_{\text {target }}(\text { control-sample })}{\mathrm{E}_{\mathrm{ref}} \Delta \mathrm{Ct}_{\mathrm{ref}}(\text { control-sample })}
$$

where $\mathrm{E}_{\text {target }}$ and $\mathrm{E}_{\mathrm{ref}}$ are the real time PCR efficiencies of the target and the reference genes, respectively. $\Delta \mathrm{Ct}_{\text {target }}$ is the difference in the threshold cycle $(\mathrm{Ct})$ of the target genes between the control and the test samples. $\Delta \mathrm{Ct}_{\mathrm{ref}}$ is the difference in the $\mathrm{Ct}$ value of the control versus the test samples with reference to $\beta$-actin.

To evaluate the expression of VEGF 165 and IL-8 at the protein level, cell culture media were collected every day for 7 days. ELISA following the manufacturer's procedures was performed to quantify the total amount of released angiogenic markers during the 7-day period. Results were normalized to the respective cell number at day 7 for each culture condition as quantified by the PicoGreen assay as described above.

\subsection{Statistical analysis}

All quantitative measurements were performed on three replicate samples. Statistical significance was evaluated using a two tailed Student's t-test. A P value of $<0.05$ was considered to be statistically different.

\section{Results}

\subsection{Hydrogel preparation and characterization}

Acrylated HA (HA-AC) was prepared via the nucleophilic substitution of NHS-AC with hydrazide-functionalized HA (HA-ADH) produced by a carbodiimide-mediated coupling reaction between HA and adipic acid dihydrazide (ADH) [18, 32]. HA-AC had a weightaverage molecular weight $\left(\mathrm{M}_{\mathrm{w}}\right)$ of $345 \mathrm{KDa}$ and the degree of acrylation of $10 \%$, as determined by GPC (data not shown) and ${ }^{1}$ H NMR (Figure S1), respectively. Separately, a carbodiimide-mediated coupling reaction between HA and a disulfide-containing dihydrazide, followed by reduction with DTT, gave rise to thiolated HA (HA-SH) [33] with an $\mathrm{M}_{\mathrm{w}}$ of $314 \mathrm{KDa}$ and $\sim 44 \%$ modification (Figure $\mathrm{S} 2$ ). 
HA-based hydrogels were prepared via a Michael-type addition reaction between HA-AC and HA-SH under physiological conditions (Scheme 1). These hydrogels exhibited an average swelling ratio of $12.9 \pm 0.1$ and a sol fraction of $18 \pm 4 \%$. Cryogenic scanning electron microscope (CryoSEM) imaging (Figure S3) revealed the presence of nanosized pores $(50-100 \mathrm{~nm})$ in the gels. Rheological analyses showed that the hydrogels had an average storage modulus (G') of $234 \pm 30 \mathrm{~Pa}$ and a loss modulus (G') of $3 \pm 2 \mathrm{~Pa}$. Analysis of the time sweep result (Figure 2A) indicates that the gelation process started $17 \mathrm{~min}$ after HA-AC and HA-SH were mixed (as evidenced by the crossover of $\mathrm{G}^{\prime}$ and $\mathrm{G}^{\prime \prime}$ in Figure $2 A)$, but was not complete until after $6 \mathrm{~h}$. Substitution of HA-AC with unmodified HA $\left(M_{w}\right.$ $=357 \mathrm{kDa}$ ) resulted in a weaker gel (Figure $2 \mathrm{~A}$ ) with the average $\mathrm{G}$ ' and G" values of $8 \pm 2$ $\mathrm{Pa}$ and $2 \pm 1 \mathrm{~Pa}$, respectively. The G' value for the control gels (HA/HA-SH) was significantly lower than that for the sample gels (HA-AC/HA-SH) at the end of the timesweep experiments $(6 \mathrm{~h})$. The insensitivity of $\mathrm{G}^{\prime}$ in the sample gels (Figure $2 \mathrm{~B}$ ) to the frequency change from 0.1 to $10 \mathrm{~Hz}$ confirmed the elastic nature of covalently crosslinked HA-AC/HA-SH networks [37]. The elastic modulus for the control samples, on the other hand, increased moderately from $5 \mathrm{~Pa}$ at $0.1 \mathrm{~Hz}$ to $14 \mathrm{~Pa}$ at $10 \mathrm{~Hz}$ over the course of the frequency sweep (31 min, Figure 2B).

Hydrogel degradation under physiologically relevant conditions with or without HAase was monitored by carbazole assay (Figure 3 ). A slight weight loss (10 $\pm 4 \mathrm{wt} \%$ ) was observed after the hydrogels were immersed in HAase-free PBS for 2 weeks. In the presence of HAase at a concentration of $5 \mathrm{U} / \mathrm{mL}$, the hydrogels became gradually smaller and completely disappeared by day 10 . Approximately $79 \mathrm{wt} \%$ of the gels was degraded by day 4 , with an average HA loss of $20 \mathrm{wt} \% /$ day from day 0 to day 4 and $2.5 \mathrm{wt} \% /$ day from day 4 to day 10 (Figure 3 ). In general, the HA hydrogels are hydrolytically stable, but could be readily degraded by HAase.

\subsection{HGP synthesis and HB-EGF release}

HP-decorated, HA-based hydrogel particles were employed in the in vitro tumor model as a growth factor depot to present HB-EGF in a sustained manner for the growth of $\mathrm{PCa}$ spheroids. Particles were synthesized via an inverse emulsion crosslinking technique [31] and heparin was covalently incorporated into the particles to specifically interact with HBEGF and to modulate its release. Owing to the high binding affinity of HB-EGF for heparin [38, 39], one milligram of HGPs sequestered up 194.1 $\pm 0.2 \mathrm{ng}$ of HB-EGF, and a high encapsulation efficiency $(97 \pm 0.1 \%)$ was observed. HB-EGF was released from HGPs at an average rate of $2.8 \mathrm{wt} \%$ per day over the entire course of the release study (Figure 4). One $\mathrm{mg}$ of particles retained $129.1 \pm 2.7 \mathrm{ng}$ of HB-EGF, releasing $33.4 \pm 1.4 \mathrm{wt} \%$ of the initially bound HB-EGF by day 13, when the experiment was terminated. Embedding the HB-EGF loaded HGPs into the HA-based hydrogel did not significantly alter the release kinetics of HB-EGF, and a sustained release profile at a rate of $2.5 \mathrm{wt} \%$ per day (Figure 4 ) was observed. After 13 days of incubation, HGP-embedded hydrogels retained $131.3 \pm 7.5 \mathrm{ng}$ of HB-EGF, releasing $32.3 \pm 3.9 \mathrm{wt} \%$ of HB-EGF initially loaded. Collectively, these results confirm that the release of HB-EGF can be modulated by HA/HP HGPs in a close to zeroorder kinetics profile.

To identify the optimal dosage to be used for the 3D bilayer cultures, a cell proliferation assay was performed in the presence of various concentrations of HB-EGF (Figure S4). A dose-dependent acceleration of cell proliferation was observed at an HBEGF concentration between 0.025 and $25 \mathrm{ng} / \mathrm{mL}$. An HB-EGF concentration of $25 \mathrm{ng} / \mathrm{mL}$ produced a $1.6 \pm 0.1$ fold increase in cell proliferation relative to the growth factor-free controls. Further increase in HB-EGF concentration to $250 \mathrm{ng} / \mathrm{mL}$ suppressed the stimulatory effect significantly (Figure S4, \#: $\mathrm{p}<0.05$ ). This information, combined with the growth factor release data, suggests that $5 \mathrm{mg}$ of HB-EGF-loaded HGPs with a daily release rate of $25 \mathrm{ng} / \mathrm{mL}$ are 
necessary to trigger the most robust inductive effect on $\mathrm{LNCaP}$ cell growth in 3D. In our control studies, LNCaP cells were cultured on 2D in an HB-EGF-conditioned medium (25 $\mathrm{ng} / \mathrm{mL}$ ) that was refreshed every day. Overall, the daily dosage of HB-EGF was the same for both $2 \mathrm{D}$ and $3 \mathrm{D}$ cultures.

\subsection{Tumor growth in bilayer HA constructs}

Bilayer constructs were prepared by overlaying the HGP-containing hydrogel on the cellladen matrix (Figure 1A). A confocal cross-sectional view of each hydrogel layer (Figure 1B (b)) showed that both HGPs and LNCaP cells were homogeneously distributed throughout the matrices.

3.3.1 Cell viability, proliferation and morphology—Live/dead staining revealed minimal cell death (stained red by PI) in both 2D and 3D cultures over the entire 7-day period (Figure 5). Live cells (stained green by SYTO13) were round and dispersed individually throughout the 3D matrix at day 1 (Figure 5G and 5J). Multicellular aggregates were observed at day 4 in 3D cultures and individual clusters increased in size over time, reaching an average diameter of $50 \mu \mathrm{m}$ at day 7 in the absence of the HB-EGF-releasing top layer (3D-CT, Figure 5H-I). Sustained presentation of HB-EGF in the bilayer model led to a rapid development of tumoroids, reaching an average diameter of $85 \mu \mathrm{m}$ after 7 days of culture (3D-HB-EGF, Figure 5K-L). Cells cultured on 2D plastic surface had a more spreadout cell body (Figure 5A-F), and the cell number increased over time, forming a confluent monolayer (Figure 5C, 5F) at day 7. Visually, more LNCaP cells were present in 2D cultures with HB-EGF (2D-HB-EGF, Figure 5E-F) as compared to those without the growth factor (2D-CT, Figure 5B-C).

Quantitative analysis revealed that cells proliferated faster in the presence of HB-EGF, both on $2 \mathrm{D}$ and in $3 \mathrm{D}$ ( $\mathrm{p}<0.05$, Figure 6$)$. By day 4 , the cell number had increased by $7.8 \pm 0.4$ and $6.0 \pm 0.5$ fold (normalized to the respective cell number at day 0 ) for $2 \mathrm{D}$ monolayer cultures with or without HB-EGF, respectively. Cells continued to proliferate on 2D, and by day 7, the cell number had increased by $13.2 \pm 0.1$ and $11.8 \pm 0.5$ fold for 2D-HB-EGF and 2D-CT, respectively. Similarly, a fold increase of $2.8 \pm 0.1$ and $2.1 \pm 0.1$ was observed at day 4 in 3D-HB-EGF and 3D-CT cultures, respectively. By day 7, a $4.8 \pm 0.4$ fold increase in cell number was detected from the 3D-HB-EGF culture, whereas cells cultured in hydrogels without HB-EGF (3D-CT) only increased in number by $2.5 \pm 0.2$ fold. Of note, cells were significantly less proliferative when cultured in $3 \mathrm{D}$ hydrogel matrices than on a 2D monolayer ( $* \mathrm{p}<0.05$, Figure 6 ), in good agreement with previously reported findings $[5,17]$.

Cell morphology and cell-cell contacts in both 2D monolayer and 3D hydrogel cultures were analyzed by confocal imaging of immunohistochemically-stained cells (Figure 7). Whereas LNCaP cells showed a spread-out morphology with an elongated cytoplasm when cultured on 2D, cells cultured in the bilayer hydrogel displayed a rounded, clustered morphology with apparent cortical organization of actin (Figure 7A). Individual spheroids contain multiple, closely packed cells with distinct nuclei and diminished cytoskeletal stress fibers. At least 25 cells were found within a single tumoroid in the 3D-HB-EGF model at day 7. Positive staining (Figure 7B) for epithelial cell-cell adhesion molecule (EpCAM) confirmed that LNCaP cells were in contact with each other through E-cadherin both on 2D (highly confluent at day 7) and in 3D cultures. Collectively, these results showed that cells cultured in the hydrogel exhibited a spherical and aggregated morphology with intimate cell-cell contact that is distinctly different from that seen in cells cultured on 2D plastic surfaces. 
3.3.2 Expression of hyaluronidase and angiogenic factors-Western blotting was performed to determine HYAL-1 expression by LNCaP cells cultured under various conditions (Figure 8). HYAL-1 was expressed by LNCaP cells cultured in both 2D and 3D environments with or without HB-EGF. By densitometry quantification, the level of HYAL-1 expression was the same for all conditions tested at day 7 (data not shown).

The expression of two important pro-angiogenic factors, VEGF $_{165}$ and IL-8, was first evaluated at the mRNA level by qPCR analysis. Our results showed that the inductive effect from HB-EGF (2D-HB-EGF vs 2D-CT) or the 3D microenvironment (3D-CT vs 2D-CT) led to a significant upregulation of $\mathrm{VEGF}_{165}$ and IL-8 expression (Figure 9A-B). These two stimulatory cues synergistically induced the most robust angiogenic propensity (3D-HBEGF). Specifically, a $14 \pm 1$ and $68 \pm 5$ fold increase was found for 3D-HB-EGF cultures at day 7 relative to $2 \mathrm{D}-\mathrm{CT}$ for $\mathrm{VEGF}_{165}$ and IL-8 expression, respectively. The expression of these pro-angiogenic factors in the bilayer system was also statistically higher than that in either 2D-HB-EGF or 3D-CT cultures ( $\mathrm{p}<0.05$, Figure 9A-B). In addition, a consistent upregulation of $\mathrm{VEGF}_{165}$ and IL-8 was observed over the entire 7-day period in 3D-HBEGF cultures (Figure 9C-D). The fold change for IL-8 was consistently higher than that seen for $\mathrm{VEGF}_{165}$.

Cellular production of pro-angiogenic factors also was assessed quantitatively at the protein level (Figure 10). Consistent with the qPCR results, 3D-HB-EGF culture conditions were most conducive to the production of $\mathrm{VEGF}_{165}$ and IL-8. After 7 days of culture in 3D-HBEGF, each cell had produced an average of $(9.0 \pm 0.2) \times 10^{-3} \mathrm{pg}$ and $(5.7 \pm 0.1) \times 10^{-3} \mathrm{pg}$ VEGF $_{165}$ and IL-8, respectively. The production of these pro-angiogenic factors in 3D-HBEGF cultures was significantly higher than that produced under the other three culture conditions ( $\mathrm{p}<0.05$, compared to 2D-CT, 2D-HB-EGF and 3D-CT, Figure 10A-B).

\section{Discussion}

The in vitro engineering of 3D tumor models reminiscent of the native tissues has emerged as an alternative strategy in cancer research $[3,6]$. Within the tumor microenvironment, the cancer cells actively communicate among themselves and with their surrounding nonmalignant stroma. Such crosstalk directs tumor growth, invasion and ultimately metastasis [26]. Therefore, to create clinically-relevant tumor masses for in vitro studies, the intimate interactions between adjacent cancer cells, as well as the crosstalks between tumor and stroma, should be considered $[26,27]$. The results presented in this study provide an important advance in the creation of a 3D bilayer platform suitable for studying tumorstromal interactions in a physiologically relevant context.

HA-based hydrogels were synthesized using HA derivatives carrying complementary functional groups via a Michael-type addition reaction between HA-AC and HA-SH. The spontaneous oxidization of sulfhydryl groups in HA-SH could contribute to the network structure, considering the large excess of reactive thiols relative to acrylates in the hydrogel mixture. Because the thiol-acrylate reaction is much faster than the oxidation reaction [40, 41], the former contributes to the faster gelation and dominates the overall mechanical properties of the resultant hydrogel networks. The slower gelation kinetics and the considerably lower storage modulus for the control gels prepared using HA-SH and unmodified HA confirm this speculation. However, the gradual and moderate increase in the stiffness of HA-AC/HA-SH gels can be attributed to the formation of a secondary disulfidelinked network [41]. Overall, the resulting elastic-solid-like hydrogel had a stiffness (G': 234 $\pm 30 \mathrm{~Pa}$ ) comparable to that of the native lymph tissue through which PCa frequently metastasizes (G': $330 \mathrm{~Pa})$ [42]. 
The hydrolytic stability and the enzymatic degradation of synthetic matrices are crucial determinants of their applicability in tumor engineering [43]. While hydrogels that maintain their long-term structural integrity are preferred for cell culture purposes, cell-mediated matrix degradation is desirable for the engineering of 3D PCa tumoroids. This is true because such processes facilitate cell migration, proliferation and matrix remodeling, ultimately leading to the formation of tumor tissues [44]. The stability of our hydrogel networks in cell culture media can be attributed to the hydrolytic stability of the resulting thioether bond and the absence of neighboring ester linkages [45]. Despite the moderate degree of chemical modifications, hydrogels synthesized from HA-AC and HA-SH can be degraded readily by HAase. In this degradation study, the HAase $(5 \mathrm{U} / \mathrm{mL})$ concentration used was significantly higher than that in bulk tissues [19, 43], but may reflect high concentrations at the tumor invasion front. Our results indicated that the biological identity of modified HA derivatives was not altered significantly, and that the resultant networks would be permissive to PCa cells because these cells express HAase (Figure 8) [19]. Collectively, the synthetic matrices provide a mechanically and biologically relevant microenvironment that is favorable for tumor growth.

It is generally accepted that cytokines secreted by stromal cells can stimulate tumor expansion and invasion, which in turn can lead to the remodeling of the stromal microenvironment in favor of cancer progression [25]. Herein, HB-EGF was employed as an inductive factor from the stroma for the growth of PCa spheroids in HA hydrogels. As demonstrated by numerous studies [46-48], the stimulatory potential of cytokines is dose and time-dependent. When presented to the cells below or above the optimal dosage or at an inadequate time, growth factors fail to elicit the desired biological responses or may induce undesirable side-effects [47]. Sustained release of growth promoting HB-EGF was achieved using HP-decorated, HA HGPs with an HP content of $0.06 \mathrm{wt} \%$. The covalently immobilized HP effectively sequesters the growth factor and modulates its release through a spatially defined and specific electrostatic interaction [38, 39]. Interestingly, HB-EGF was released from HGP suspension and the HGP-embedded hydrogels at comparable rates. This can be attributed to the small size of HB-EGF (14-19 KDa [49], corresponding to Stokes's radii [50] of 2.8-3.2 nm) compared to the pore size of the inter-particle network (Figure S3). Moreover, considering the isoelectric point (pI) of HB-EGF (7.2-7.8) [51] and the $\mathrm{pH}$ of the cell culture medium (7.4), one can easily conclude that there are no apparent electrostatic interactions between the HP-free HA network surrounding HGPs and HB-EGF. Therefore, once HB-EGF was released from HA/HP HGPs, the growth factor molecules diffused through the secondary network without any additional steric hindrance or electrostatic restriction. In general, this particle-based releasing system enabled the controlled presentation of HB-EGF to the encapsulated LNCaP cells over the entire culture period.

HB-EGF interactions with PCa cells in the tumor microenvironment [28] have been shown to accelerate cell growth. The bilayer culture platform was designed to recapitulate the $\mathrm{PCa}$ microenvironment by fostering intimate cell-matrix and cell-cell interactions. The bottom layer resembles the tumor tissue, and the top layer mimics stromal tissue to provide the inductive cues to the entrapped LNCaP cells. In related studies (not shown and [28, 52]), we and others have shown that LNCaP cells express low levels of both EGFR1 and ErbB-2 receptor kinases, providing them with the ability to respond to EGF family members. Thus the bilayer 3D model provides several components reminiscent of the native tumor microenvironment: proximally growing PCa cells with stromal cytokines, a controlled release of HB-EGF, cancer cells expressing receptors for EGF family members, and a matrix derived from a cell-responsive, native ECM constituent.

In agreement with previous studies [5], LNCaP cells proliferated more slowly in 3D HA hydrogels than on 2D plastics. Foster and colleagues found that PCa cells grow more slowly 
in vivo than on a 2D plastic cell culture [53]. Therefore, the observed slower growth rate in HA gels more closely resembles the tumor growth in vivo. The 3D confinement imposed by the matrices surrounding the cells may have restricted cell proliferation [54]. Because individual LNCaP cells were evenly distributed throughout the HA matrix at the beginning of the 3D culture, the formation and expansion of tumoroids cannot be attributed exclusively to cell proliferation, considering the low proliferative potential of LNCaP cells cultured in the 3D matrix (Figure 6) and the large number of cells found in individual tumoroids with a closely packed structure (Figure 7). Merging of tumoroids in close proximity, facilitated by the matrix degradation (see below), also could contribute to their size expansion.

HYAL-1 is abundant in the tissue of PCa and can utilize HA of any size as a substrate, generating predominantly tetrasaccharides [55]. Western blot analysis (Figure 8) indicates that HYAL-1 was highly expressed by LNCaP cells cultured in the 3D environment. The degradation of the HA matrix by cell-secreted HYAL-1 can create a porous pathway to facilitate the merging of neighboring tumoroids. In addition, glutathione (GSH) secreted by LNCaP cells [56] may participate in the matrix remolding process by reducing the disulfide bond formed through HA-SH that partially contributed to the matrix integrity. An elevated level of GSH is associated with the evolution of drug-resistant PCa cell lines (LNCaP and DU-145 upon chemotherapeutic treatment) [56, 57]. Therefore, the extracellularly released GSH from LNCaP cells also could facilitate the merging of tumoroids. Collectively, both the HAase and GSH expressed by LNCaP cells may participate in the process of HA matrix remodeling, which ultimately resulted in the umoroid size expansion by promoting a merger of tumoroids. It is notable that the overall integrity of the hydrogel was not compromised by the locally cell-expressed HAase or GSH (Figure S5).

It is worth mentioning that prolonged cultivation of the tumoroids beyond day $7 \mathrm{did}$ not further increase the size of the cell clusters, nor did cells in the center of the tumoroids become necrotic or form lumens (data not shown). Previous studies show that elastic stress gradually accumulates around the in vitro tumor spheroids as a result of the progressive displacement of the matrices by the growing cellular mass [58, 59]; tumoroids stop expanding when a growth-inhibitory threshold level of elastic stress is attained [58]. The inhibitory elastic stress imposed by the matrices was suggested to limit cell proliferation, ultimately leading to cell apoptosis through a mitochondrial pathway [60]. In our case, the HA matrix may impose elastic forces on the growing LNCaP tumoroids, thereby limiting cell growth and preventing the merger of neighboring tumoroids after the threshold spheroid size was reached. The competition for essential nutrients within the cell-laden 3D matrix was intensified gradually with the expansion of tumoroids and with the increasing diffusion distances that are required for nutrients to reach the center of tumoroids. As a self-protective mechanism, the tumoroids stopped expanding [61, 62]. We anticipate that culturing cells in our bilayer system under optimal nutrient and oxygen conditions could lead to larger spheroids with necrotic regions.

Angiogenesis refers to the formation of new blood vessels from the pre-existing vasculature [63], and is critical for sustained tumor progression, invasion and metastasis [63]. $\mathrm{VEGF}_{165}$, a potent and prevalent isoform in the VEGF family, is widely expressed by stressed tumor cells and its production in the tumor microenvironment increases microvascular permeability, induces endothelial cell ingrowth and proliferation, and promotes endothelial cell survival [64]. IL-8 also has been suggested to play a crucial role in mediating tumor angiogenesis [65]. Our results show that both the soluble HB-EGF and the 3D microenvironment induced an upregulation of $\mathrm{VEGF}_{165}$ and IL-8 expression. The most robust angiogenic induction was observed when both environmental cues were present. In addition to its mitogenic effect, HB-EGF plays an important role in tumor angiogenesis by promoting the expression for $\mathrm{VEGF}_{165}$ and IL-8 from cancer cells $[66,67]$. The inductive 
effect of HB-EGF on the secretion of angiogenic factors was shown to be regulated through its interaction with the cell surface EGF-receptors $[68,69]$. Separately, as mentioned above, the gradually accumulated stress on available nutrients within the 3D matrix triggers cellular stress and alters gene expression, which ultimately elevates the expression and stabilization of pro-angiogenic factors [64]. Similar inductive effects also were observed by culturing cancer cells in collagen gels [3] and in scaffolds fabricated from PLGA [6]. Finally, small HA fragments containing 4 to 25 disaccharide repeats generated from HAase-mediated matrix degradation were shown to be angiogenic $[23,70]$. Our results confirm that the HBEGF released from HGPs, the stress induced by nutrients limitation and the degraded HA fragments collectively contribute to the increased angiogenic potential exhibited from 3DHB-EGF tumoroid cultures.

Although the bilayer model described here recaptures the tumor-stromal cell communication, it does not recapitulate the spatial distribution of cancer and the stromal cells in the native tissue where they may be in direct contact. Another limitation of the current hydrogel culture system is the lack of matrix metalloproteinase (MMP)-degradable motifs. Considering the crucial roles MMPs play in cancer progression and invasion in vivo [71], it is important that MMP-sensitive motifs be incorporated in our HA matrices. In our future studies, tumor cells will be cultured in the presence of randomly distributed EGFreleasing HGPs in a single hydrogel construct that can be degraded by MMPs as well as HAase. Using this model, we will investigate the engagement of EGFR in EGF signaling in a biologically-relevant 3D environment.

\section{Conclusions}

An HA-based, bilayer culture platform was developed for the 3D culture of PCa cells. This platform recapitulates the many of the characteristics of $\mathrm{PCa}$ and facilitates the crosstalk between the tumor and its surrounding stroma via growth factor signaling. This bilayer hydrogel system supports the growth and organization of LNCaP cells. Tumor spheroids with an average diameter of $85 \mu \mathrm{m}$ were detected after 7 days of culture in the presence of temporally presented HB-EGF. Cells in these spheroids expressed cortical actin and Ecadherin at cell-cell junctions. Cells cultured under the biomimetic conditions expressed a higher level of pro-angiogenic factors. The 3D bilayer model provides an engineering advance that can mimic the native carcinoma and can be used as an in vitro model for the screening of cell responses to growth factors and for anticancer drugs such as those targeting EGFRs.

\section{Supplementary Material}

Refer to Web version on PubMed Central for supplementary material.

\section{Acknowledgments}

We thank Dr. Jeff Caplan for his expert assistance with the confocal imaging and Genzyme for generously providing HA. This work was supported in part by National Institutes of Health (NIH, P20RR016458, P20RR017716, R01DC008965 and P01CA098912) and Delaware Health Science Alliance (DHSA).

\section{References}

1. Hutmacher DW. Biomaterials offer cancer research the third dimension. Nat Mater. 2010; 9:90-3. [PubMed: 20094076]

2. Verbridge SS, Chandler EM, Fischbach C. Tissue-engineered three-dimensional tumor models to study tumor angiogenesis. Tissue Eng Part A. 2010; 16:2147-52. [PubMed: 20214471] 
3. Szot CS, Buchanan CF, Freeman JW, Rylander MN. 3D in vitro bioengineered tumors based on collagen I hydrogels. Biomaterials. 2011; 32:7905-12. [PubMed: 21782234]

4. Ghajar CM, Bissell MJ. Tumor engineering: the other face of tissue engineering. Tissue Eng Part A. 2010; 16:2153-6. [PubMed: 20214448]

5. Hutmacher DW, Loessner D, Rizzi S, Kaplan DL, Mooney DJ, Clements JA. Can tissue engineering concepts advance tumor biology research? Trends Biotechnol. 2010; 28:125-33. [PubMed: 20056286]

6. Fischbach C, Chen R, Matsumoto T, Schmelzle T, Brugge JS, Polverini PJ, et al. Engineering tumors with 3D scaffolds. Nat Methods. 2007; 4:855-60. [PubMed: 17767164]

7. Chen L, Xiao Z, Meng Y, Zhao Y, Han J, Su G, et al. The enhancement of cancer stem cell properties of MCF-7 cells in 3D collagen scaffolds for modeling of cancer and anti-cancer drugs. Biomaterials. 2012; 33:1437-44. [PubMed: 22078807]

8. Ananthanarayanan B, Kim Y, Kumar S. Elucidating the mechanobiology of malignant brain tumors using a brain matrix-mimetic hyaluronic acid hydrogel platform. Biomaterials. 2011; 32:7913-23. [PubMed: 21820737]

9. Harma V, Virtanen J, Makela R, Happonen A, Mpindi J-P, Knuuttila M, et al. A comprehensive panel of three-dimensional models for studies of prostate cancer growth, invasion and drug responses. PLoS ONE. 2010:5.

10. Ingber DE. Can cancer be reversed by engineering the tumor microenvironment? Semin Cancer Biol. 2008; 18:356-64. [PubMed: 18472275]

11. Partanen JI, Nieminen AI, Makela TP, Klefstrom J. Suppression of oncogenic properties of c-Myc by LKB1-controlled epithelial organization. Proc Natl Acad Sci U S A. 2007; 104:14694-9. [PubMed: 17766436]

12. Cross VL, Zheng Y, Choi NW, Verbridge SS, Sutermaster BA, Bonassar LJ, et al. Dense type I collagen matrices that support cellular remodeling and microfabrication for studies of tumor angiogenesis and vasculogenesis in vitro. Biomaterials. 2010; 31:8596-607. [PubMed: 20727585]

13. Loessner D, Stok KS, Lutolf MP, Hutmacher DW, Clements JA, Rizzi SC. Bioengineered 3D platform to explore cell-ECM interactions and drug resistance of epithelial ovarian cancer cells. Biomaterials. 2010; 31:8494-506. [PubMed: 20709389]

14. Kenny PA, Lee GY, Myers CA, Neve RM, Semeiks JR, Spellman PT, et al. The morphologies of breast cancer cell lines in three-dimensional assays correlate with their profiles of gene expression. Mol Oncol. 2007; 1:84-96. [PubMed: 18516279]

15. Sieh S, Lubik AA, Clements JA, Nelson CC, Hutmacher DW. Interactions between human osteoblasts and prostate cancer cells in a novel 3D in vitro model. Organogenesis. 2010; 6:181-8. [PubMed: 21197221]

16. Sell SA, Wolfe PS, Garg K, McCool JM, Rodriguez IA, Bowlin GL. The Use of Natural Polymers in Tissue Engineering: A Focus on Electrospun Extracellular Matrix Analogues. Polymers. 2010; 2:522-53.

17. Gurski LA, Jha AK, Zhang C, Jia XQ, Farach-Carson MC. Hyaluronic acid-based hydrogels as 3D matrices for in vitro evaluation of chemotherapeutic drugs using poorly adherent prostate cancer cells. Biomaterials. 2009; 30:6076-85. [PubMed: 19695694]

18. Jia XQ, Yeo Y, Clifton RJ, Jiao T, Kohane DS, Kobler JB, et al. Hyaluronic acid-based microgels and microgel networks for vocal fold regeneration. Biomacromolecules. 2006; 7:3336-44. [PubMed: 17154461]

19. Lokeshwar VB, Cerwinka WH, Isoyama T, Lokeshwar BL. HYAL1 hyaluronidase in prostate cancer: A tumor promoter and suppressor. Cancer Res. 2005; 65:7782-9. [PubMed: 16140946]

20. Lokeshwar VB, Rubinowicz D, Schroeder GL, Forgacs E, Minna JD, Block NL, et al. Stromal and epithelial expression of tumor markers hyaluronic acid and HYAL1 hyaluronidase in prostate cancer. J Biol Chem. 2001; 276:11922-32. [PubMed: 11278412]

21. Liu DC, Pearlman E, Diaconu E, Guo K, Mori H, Haqqi T, et al. Expression of hyaluronidase by tumor cells induces angiogenesis in vivo. Proc Natl Acad Sci U S A. 1996; 93:7832-7. [PubMed: 8755562]

22. Hobarth K, Maier U, Marberger M. Topical chemoprophylaxis of superficial bladder cancer with mitomycin C and adjuvant hyaluronidase. Eur Urol. 1992; 21:206-10. [PubMed: 1499626] 
23. Lees VC, Fan TPD, West DC. Angiogenesis in a delayed revascularization model is accelerated by angiogenic oligosaccharides of hyaluronan. Lab Invest. 1995; 73:259-66. [PubMed: 7543630]

24. Bhowmick NA, Moses HL. Tumor-stroma interactions. Curr Opin Genet Dev. 2005; 15:97-101. [PubMed: 15661539]

25. Verona EV, Elkahloun AG, Yang J, Bandyopadhyay A, Yeh IT, Sun L-Z. Transforming growth factor-beta signaling in prostate stromal cells supports prostate carcinoma growth by up-regulating stromal genes related to tissue remodeling. Cancer Res. 2007; 67:5737-46. [PubMed: 17575140]

26. Joyce JA, Pollard JW. Microenvironmental regulation of metastasis. Nat Rev Cancer. 2009; 9:23952. [PubMed: 19279573]

27. Murata T, Mizushima H, Chinen I, Moribe H, Yagi S, Hoffman RM, et al. HB-EGF and PDGF mediate reciprocal interactions of carcinoma cells with cancer-associated fibroblasts to support progression of uterine cervical cancers. Cancer Res. 2011; 71:6633-42. [PubMed: 22009535]

28. Freeman MR, Paul S, Kaefer M, Ishikawa M, Adam RM, Renshaw AA, et al. Heparin-binding EGF-Like growth factor in the human prostate: Synthesis predominantly by interstitial and vascular smooth muscle cells and action as a carcinoma cell mitogen. J cell Biochem. 1998; 68:328-38. [PubMed: 9518259]

29. Iwamoto R, Mekada E. Heparin-binding EGF-like growth factor: a juxtacrine growth factor. Cytokine Growth F R. 2000; 11:335-44.

30. Ongusaha PP, Kwak JC, Zwible AJ, Macip S, Higashiyama S, Taniguchi N, et al. HB-EGF is a potent inducer of tumor growth and angiogenesis. Cancer Res. 2004; 64:5283-90. [PubMed: 15289334]

31. Xu X, Jha AK, Duncan RL, Jia XQ. Heparin-decorated, hyaluronic acid-based hydrogel particles for the controlled release of bone morphogenetic protein 2. Acta Biomater. 2011; 7:3050-9. [PubMed: 21550426]

32. Lei YG, Gojgini S, Lam J, Segura T. The spreading, migration and proliferation of mouse mesenchymal stem cells cultured inside hyaluronic acid hydrogels. Biomaterials. 2011; 32:39-47. [PubMed: 20933268]

33. Shu XZ, Liu YC, Luo Y, Roberts MC, Prestwich GD. Disulfide cross-linked hyaluronan hydrogels. Biomacromolecules. 2002; 3:1304-11. [PubMed: 12425669]

34. Bitter T, Muir HM. A modified uronic acid carbazole reaction. Anal Biochem. 1962; 4:330-\&. [PubMed: 13971270]

35. Jha AK, Yang WD, Kirn-Safran CB, Farach-Carson MC, Jia XQ. Perlecan domain I-conjugated, hyaluronic acid-based hydrogel particles for enhanced chondrogenic differentiation via BMP-2 release. Biomaterials. 2009; 30:6964-75. [PubMed: 19775743]

36. Muir C, Chung LWK, Carson DD, Farach-Carson MC. Hypoxia increases VEGF-A production by prostate cancer and bone marrow stromal cells and initiates paracrine activation of bone marrow endothelial cells. Clin Exp Metastasis. 2006; 23:75-86. [PubMed: 16826426]

37. Jeong KJ, Panitch A. Interplay between covalent and physical interactions within environment sensitive hydrogels. Biomacromolecules. 2009; 10:1090-9. [PubMed: 19301930]

38. Capila I, Linhardt RJ. Heparin - Protein interactions. Angew Chem-Int Edit. 2002; 41:391-412.

39. Nugent MA, Edelman ER. Kinetics of basic fibroblast growth factor binding to its receptor and heparan sulfate proteoglycan: a mechanism for cooperactivity. Biochemistry. 1992; 31:8876-83. [PubMed: 1390674]

40. Shu XZ, Liu YC, Palumbo FS, Lu Y, Prestwich GD. In situ crosslinkable hyaluronan hydrogels for tissue engineering. Biomaterials. 2004; 25:1339-48. [PubMed: 14643608]

41. Ghosh K, Shu XZ, Mou R, Lombardi J, Prestwich GD, Rafailovich MH, et al. Rheological characterization of in situ cross-linkable hyaluronan hydrogels. Biomacromolecules. 2005; 6:2857-65. [PubMed: 16153128]

42. Levental I, Georges PC, Janmey PA. Soft biological materials and their impact on cell function. Soft Matter. 2007; 3:299-306.

43. Kim J, Kim IS, Cho TH, Lee KB, Hwang SJ, Tae G, et al. Bone regeneration using hyaluronic acid-based hydrogel with bone morphogenic protein-2 and human mesenchymal stem cells. Biomaterials. 2007; 28:1830-7. [PubMed: 17208295] 
44. Liu Y, Shu XZ, Prestwich GD. Tumor engineering: Orthotopic cancer models in mice using cellloaded, injectable, cross-linked hyaluronan-derived hydrogels. Tissue Eng. 2007; 13:1091-101. [PubMed: 17582839]

45. Schoenmakers RG, van de Wetering P, Elbert DL, Hubbell JA. The effect of the linker on the hydrolysis rate of drug-linked ester bonds. J Control Release. 2004; 95:291-300. [PubMed: 14980777]

46. Bessa PC, Casal M, Reis RL. Bone morphogenetic proteins in tissue engineering: the road from laboratory to clinic, part II (BMP delivery). J Tissue Eng Regen Med. 2008; 2:81-96. [PubMed: 18383454]

47. Shields LBE, Raque GH, Glassman SD, Campbell M, Vitaz T, Harpring J, et al. Adverse effects associated with high-dose recombinant human bone morphogenetic protein-2 use in anterior cervical spine fusion. Spine. 2006; 31:542-7. [PubMed: 16508549]

48. Winn SR, Uludag H, Hollinger JO. Sustained release emphasizing recombinant human bone morphogenetic protein-2. Advanced Drug Delivery Reviews. 1998; 31:303-18. [PubMed: 10837631]

49. Goishi K, Higashiyama S, Klagsbrun M, Nakano N, Umata T, Ishikawa M, et al. Phorbol ester induces the rapid processing of cell surface heparin-binding EGF-like growth factor: conversion from juxtacrine to paracrine growth factor activity. Mol Biol Cell. 1995; 6:967-80. [PubMed: 7579712]

50. Bert JL, Pearce RH, Mathieson JM, Warner SJ. Characterization of collagenous meshworks by volume exclusion of dextrans. Biochem J. 1980; 191:761-8. [PubMed: 6169339]

51. Higashiyama S, Lau K, Besner GE, Abraham JA, Klagsbrun M. Structure of heparin-binding EGFlike growth factor. Multiple forms, primary structure, and glycosylation of the mature protein. J Biol Chem. 1992; 267:6205-12. [PubMed: 1556128]

52. Dorai T, Dutcher JP, Dempster DW, Wiernik PH. Therapeutic potential of curcumin in prostate cancer - IV: Interference with the osteomimetic properties of hormone refractory C4-2B prostate cancer cells. Prostate. 2004; 60:1-17. [PubMed: 15129424]

53. Foster BA, Gingrich JR, Kwon ED, Madias C, Greenberg NM. Characterization of prostatic epithelial cell lines derived from transgenic adenocarcinoma of the mouse prostate (TRAMP) model. Cancer Research. 1997; 57:3325-30. [PubMed: 9269988]

54. Wang LS, Chung JE, Chan PPY, Kurisawa M. Injectable biodegradable hydrogels with tunable mechanical properties for the stimulation of neurogenesic differentiation of human mesenchymal stem cells in 3D culture. Biomaterials. 2010; 31:1148-57. [PubMed: 19892395]

55. Sugahara KN, Hirata T, Hayasaka H, Stern R, Murai T, Miyasaka M. Tumor cells enhance their own CD44 cleavage and motility by generating hyaluronan fragments. J Biol Chem. 2006; 281:5861-8. [PubMed: 16407205]

56. Ripple M, Mulcahy RT, Wilding G. Characteristics of the glutathione/glutathione-S-transferase detoxification system in melphalan resistant human prostate cancer cells. J Urology. 1993; 150:209-14.

57. Bailey HH, Gipp JJ, Ripple M, Wilding G, Mulcahy RT. Increase in gamma-glutamylcysteine synthetase activity and steady-state messenger RNA levels in melphalan-resistant DU-145 human prostate carcinoma cells expressing elevated glutathione levels. Cancer Res. 1992; 52:5115-8. [PubMed: 1355406]

58. Helmlinger G, Netti PA, Lichtenbeld HC, Melder RJ, Jain RK. Solid stress inhibits the growth of multicellular tumor spheroids. Nat Biotechnol. 1997; 15:778-83. [PubMed: 9255794]

59. Butcher DT, Alliston T, Weaver VM. A tense situation: forcing tumour progression. Nat Rev Cancer. 2009; 9:108-22. [PubMed: 19165226]

60. Cheng G, Tse J, Jain RK, Munn LL. Micro-Environmental mechanical stress controls tumor spheroid size and morphology by suppressing proliferation and inducing apoptosis in cancer cells. PLoS ONE. 2009; 4

61. Folkman J, Watson K, Ingber D, Hanahan D. Induction of angiogenesis during the transition from hyperplasia to neoplasia. Nature. 1989; 339:58-61. [PubMed: 2469964] 
62. Kisker O, Onizuka S, Banyard J, Komiyama T, Becker CM, Achilles EG, et al. Generation of multiple angiogenesis inhibitors by human pancreatic cancer. Cancer Res. 2001; 61:7298-304. [PubMed: 11585769]

63. Sokoloff MH, Chung LWK. Targeting angiogenic pathways involving tumor-stromal interaction to treat advanced human prostate cancer. Cancer Metastasis Rev. 1998; 17:307-15. [PubMed: 10453273]

64. Marjon PL, Bobrovnikova-Marjon EV, Abcouwer SF. Expression of the proangiogenic factors vascular endothelial growth factor and interleukin-8/CXCL8 by human breast carcinomas is responsive to nutrient deprivation and endoplasmic reticulum stress. Mol Cancer. 2004; 3:4. [PubMed: 14738568]

65. Bao B-Y, Yao J, Lee Y-F. 1 alpha, 25-dihydroxyvitamin D-3 suppresses interleukin-8-mediated prostate cancer cell angiogenesis. Carcinogenesis. 2006; 27:1883-93. [PubMed: 16624828]

66. McGovern T, Risse P-A, Tsuchiya K, Hassan M, Frigola G, Martin JG. LTD(4) induces HB-EGFdependent CXCL8 release through EGFR activation in human bronchial epithelial cells. Am J Physiol Lung Cell Mol Physiol. 2010; 299:L808-L15. [PubMed: 20889674]

67. Yagi H, Yotsumoto F, Miyamoto S. Heparin-binding epidermal growth factor-like growth factor promotes transcoelomic metastasis in ovarian cancer through epithelial-mesenchymal transition. Mol Cancer Ther. 2008; 7:3441-51. [PubMed: 18852147]

68. Fujiyama S, Matsubara H, Nozawa Y, Maruyama K, Mori Y, Tsutsumi Y, et al. Angiotensin AT(1) and AT(2) receptors differentially regulate angiopoietin-2 and vascular endothelial growth factor expression and angiogenesis by modulating heparin binding-epidermal growth factor (EGF)mediated EGF receptor transactivation. Circ Res. 2001; 88:22-9. [PubMed: 11139469]

69. Zhang Y, Wang L, Zhang M, Jin M, Bai C, Wang X. Potential mechanism of interleukin-8 production from lung cancer cells: an involvement of EGF-EGFRPI3K-Akt-Erk pathway. J Cell Physiol. 2011; 227:35-43. [PubMed: 21412767]

70. West DC, Hampson IN, Arnold F, Kumar S. Angiogenesis induced by degradation products of hyaluronic acid. Science. 1985; 228:1324-6. [PubMed: 2408340]

71. Crawford HC, Matrisian LM. Tumor and stromal expression of matrix metalloproteinases and their role in tumor progression. Invasion Metastasis. 1994; 14:234-45. [PubMed: 7657516] 

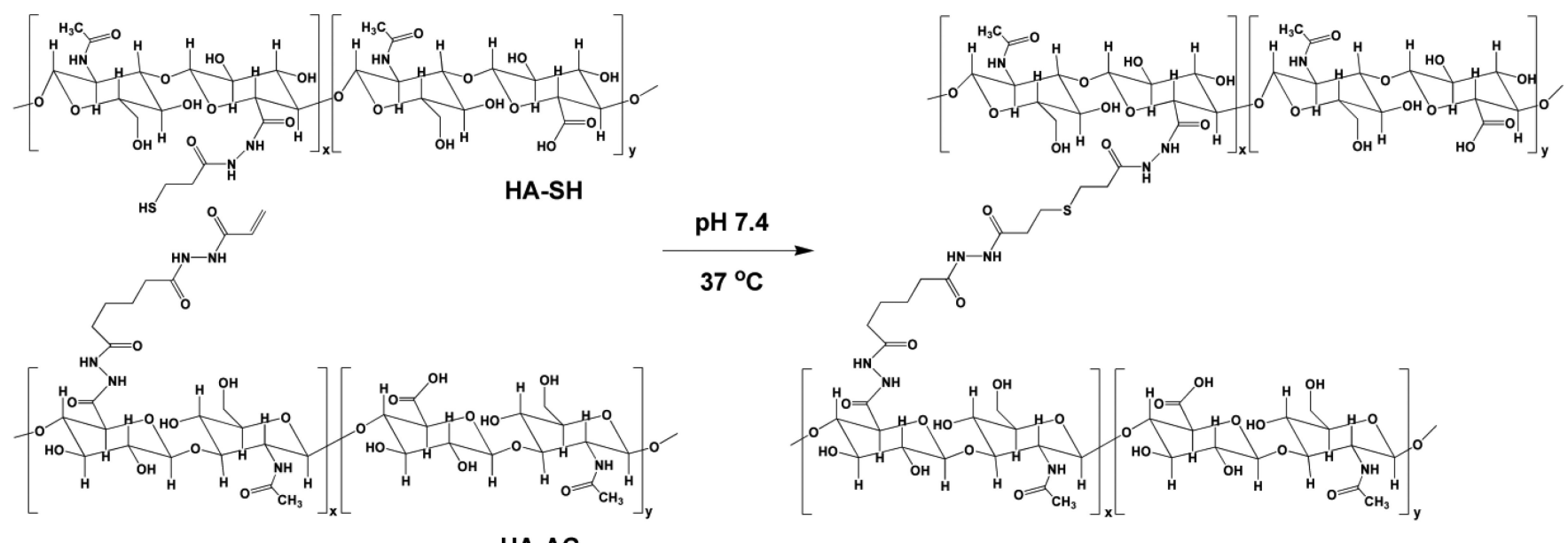

HA-AC

Scheme 1.

Synthesis of HA-based hydrogels via the covalent crosslinking of HA-AC and HA-SH.

Hydrolytically stable thioether bonds with neighboring hydrazide amides are formed at the crosslinking points. 

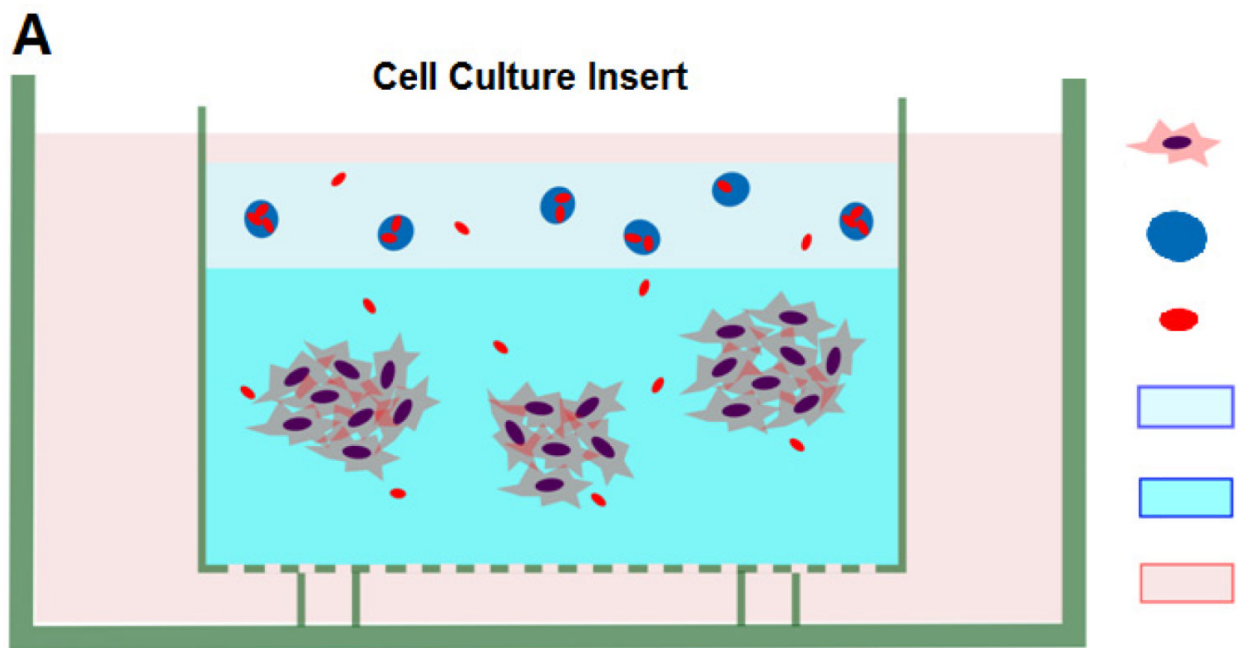

LNCaP prostate cancer cell

HA/HP HGPs

HB-EGF

Hydrogel top layer

Hydrogel bottom layer

24 Well Plate

B

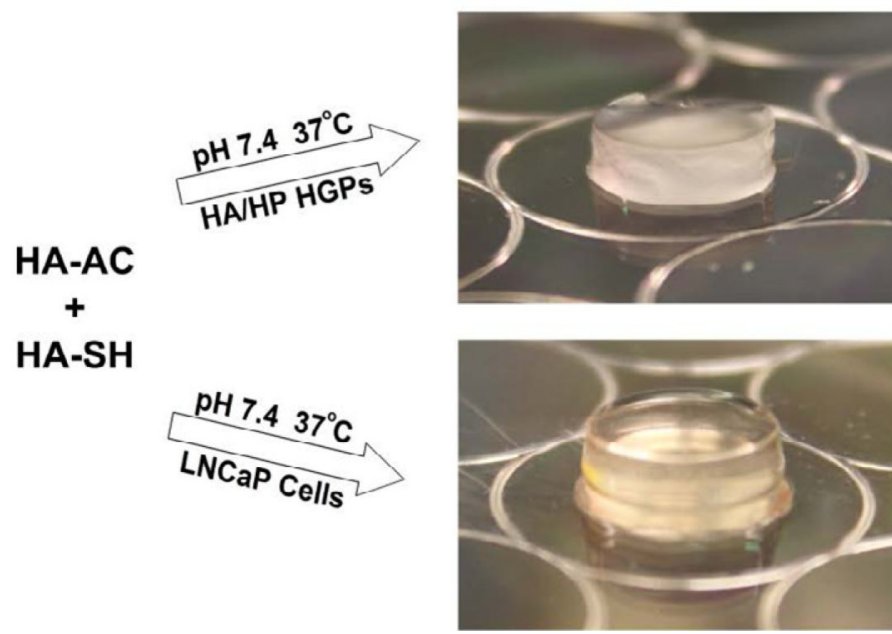

(b)
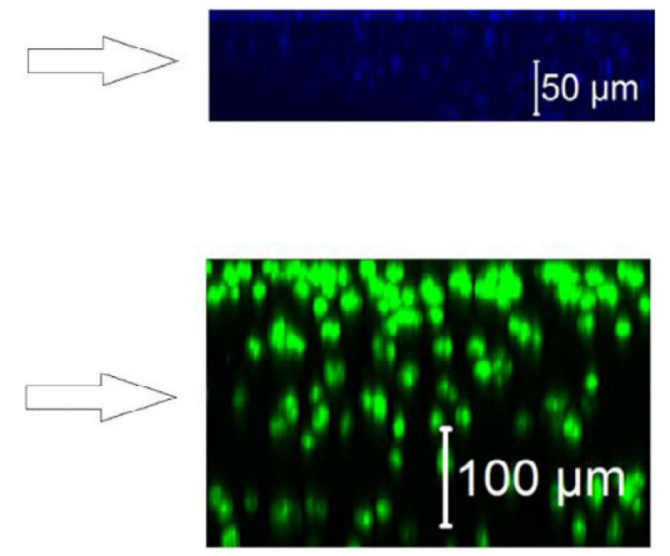

Figure 1.

Three-dimensional bilayer hydrogel culture (3D-HB-EGF) for the growth of tumoroids from LNCaP prostate cancer cells. (A) Schematic illustration of the bilayer hydrogel culture system; (B) Hydrogel formation and construct assembly: (a) HA hydrogels containing HBEGF-loaded HGPs (top) or LNCaP cells (bottom) were prepared separately and subsequently stacked; (b) Confocal images of individual hydrogel layers containing cascade blue-stained HGPs (top) or SYTO13/PI stained LNCaP cells cultured at day 1 (bottom). 

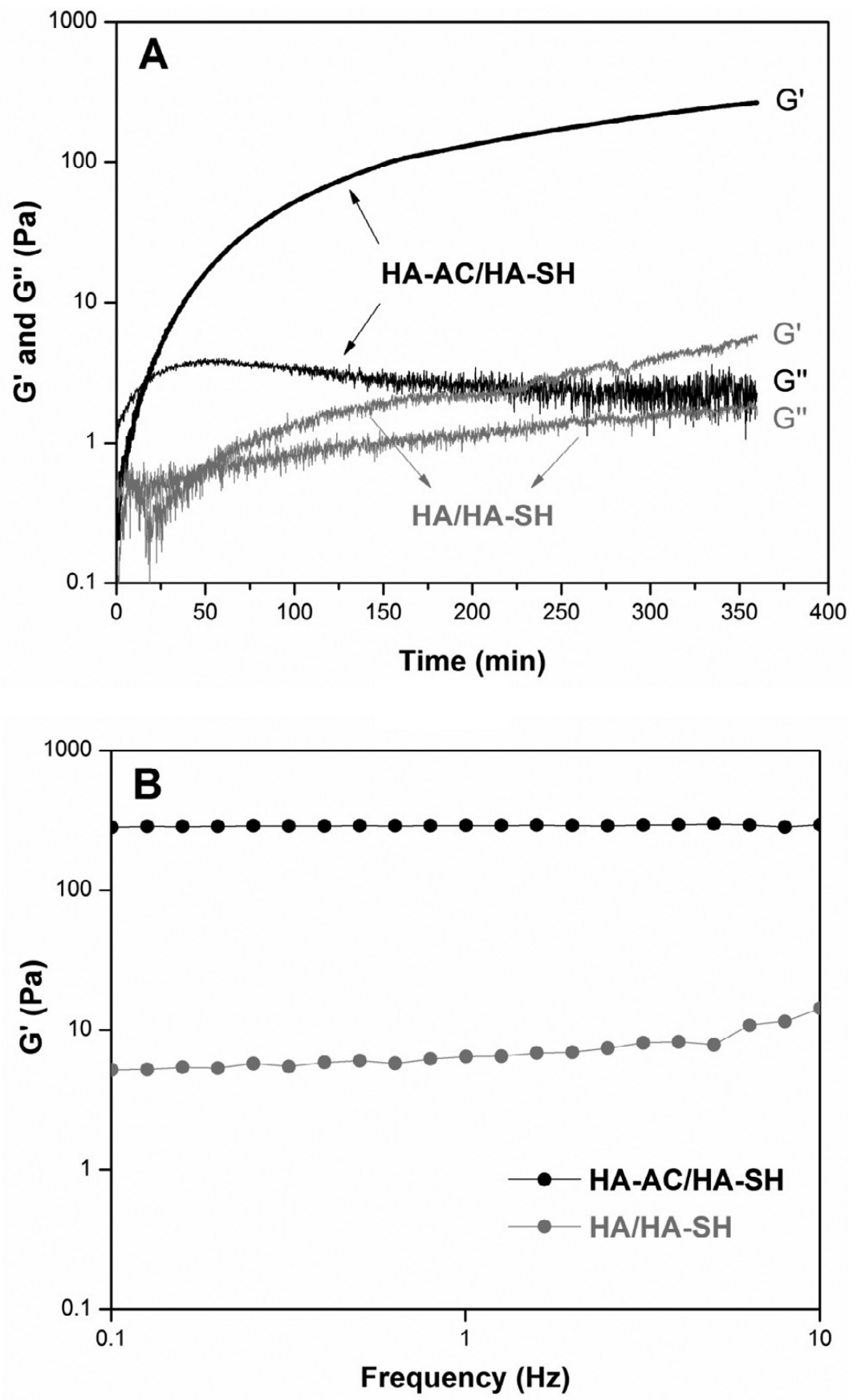

Figure 2.

Representative rheological measurements of HA hydrogels prepared from HA-AC and HASH (black symbols) and control samples prepared using HA and HA-SH (gray symbols). (A): Time sweep; (B): Frequency sweep. 


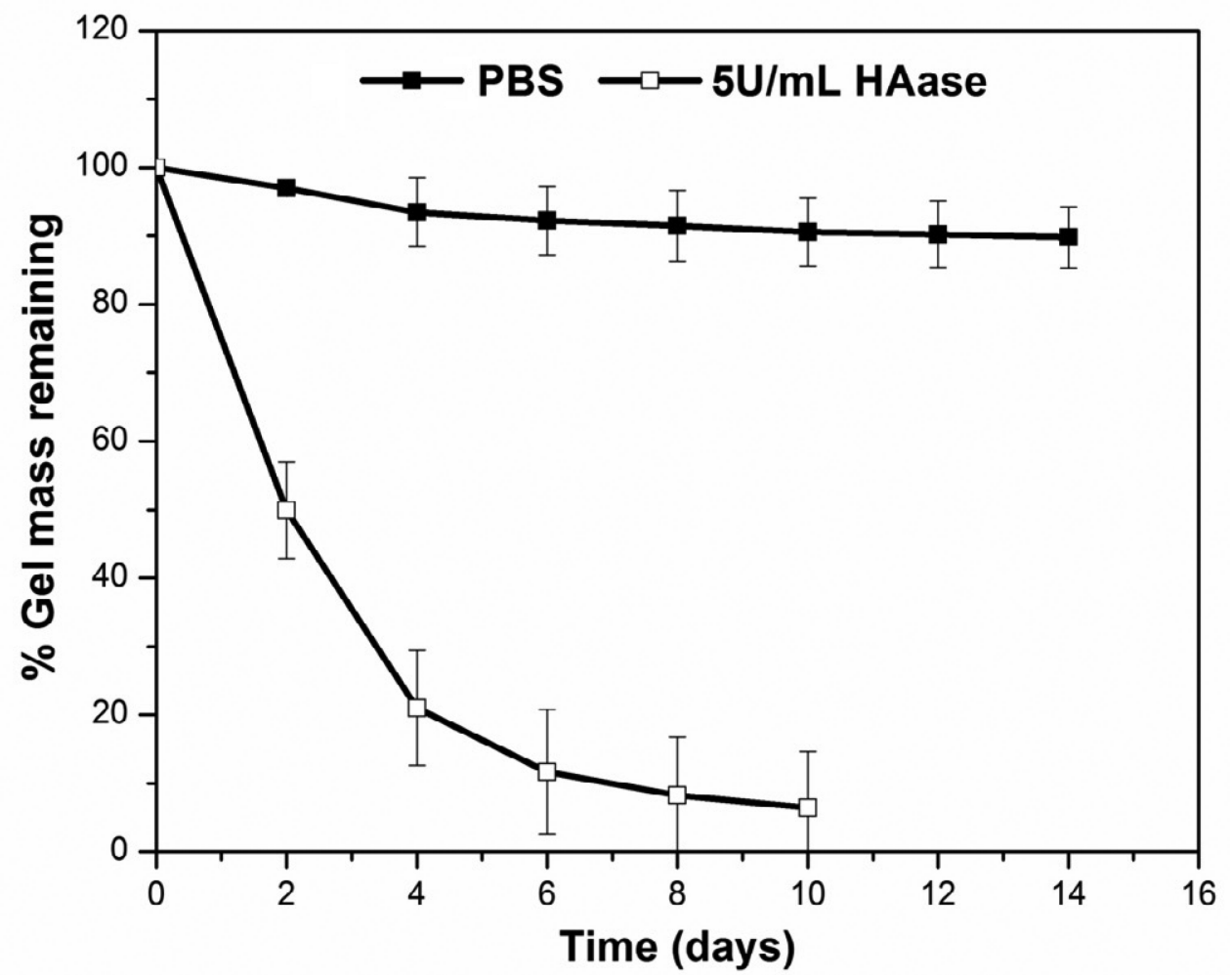

Figure 3.

Hydrolytic stability and enzymatic degradability of HA hydrogels. The gel mass as a function of incubation time in PBS in the presence (open symbol) or absence (filled symbol) of HAase $(5 \mathrm{U} / \mathrm{mL})$ was monitored by the carbazole assay. 


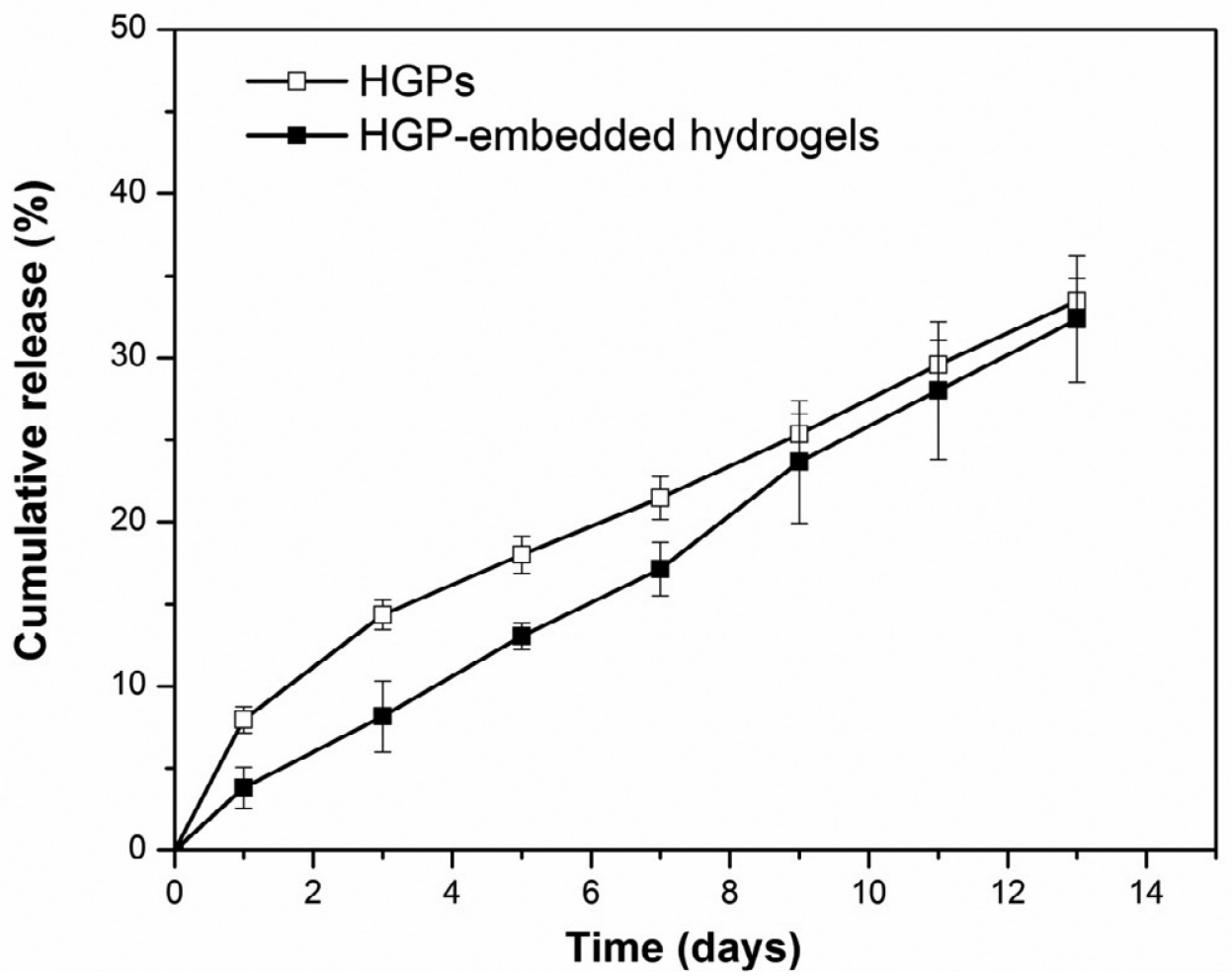

Figure 4.

Cumulative release of HB-EGF from HGPs (open symbols) and HGP-embedded hydrogels (filled symbols) for up to 13 days. 

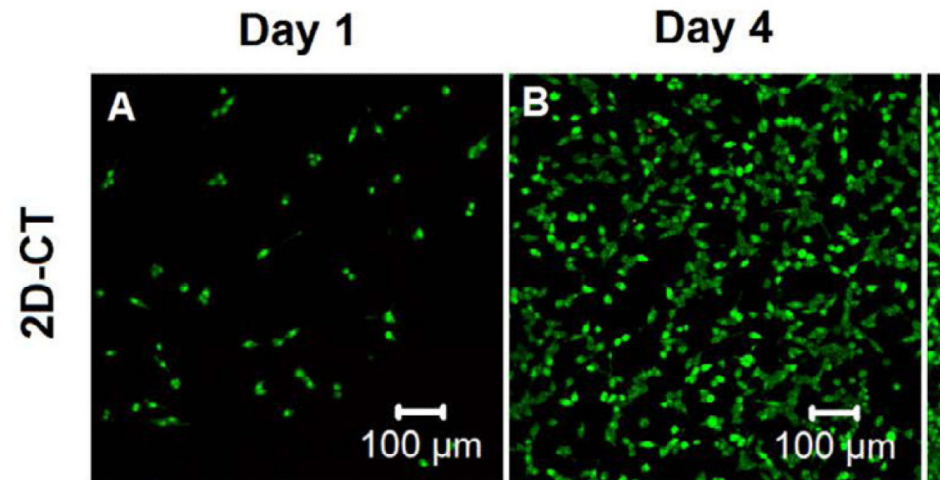

Day 7
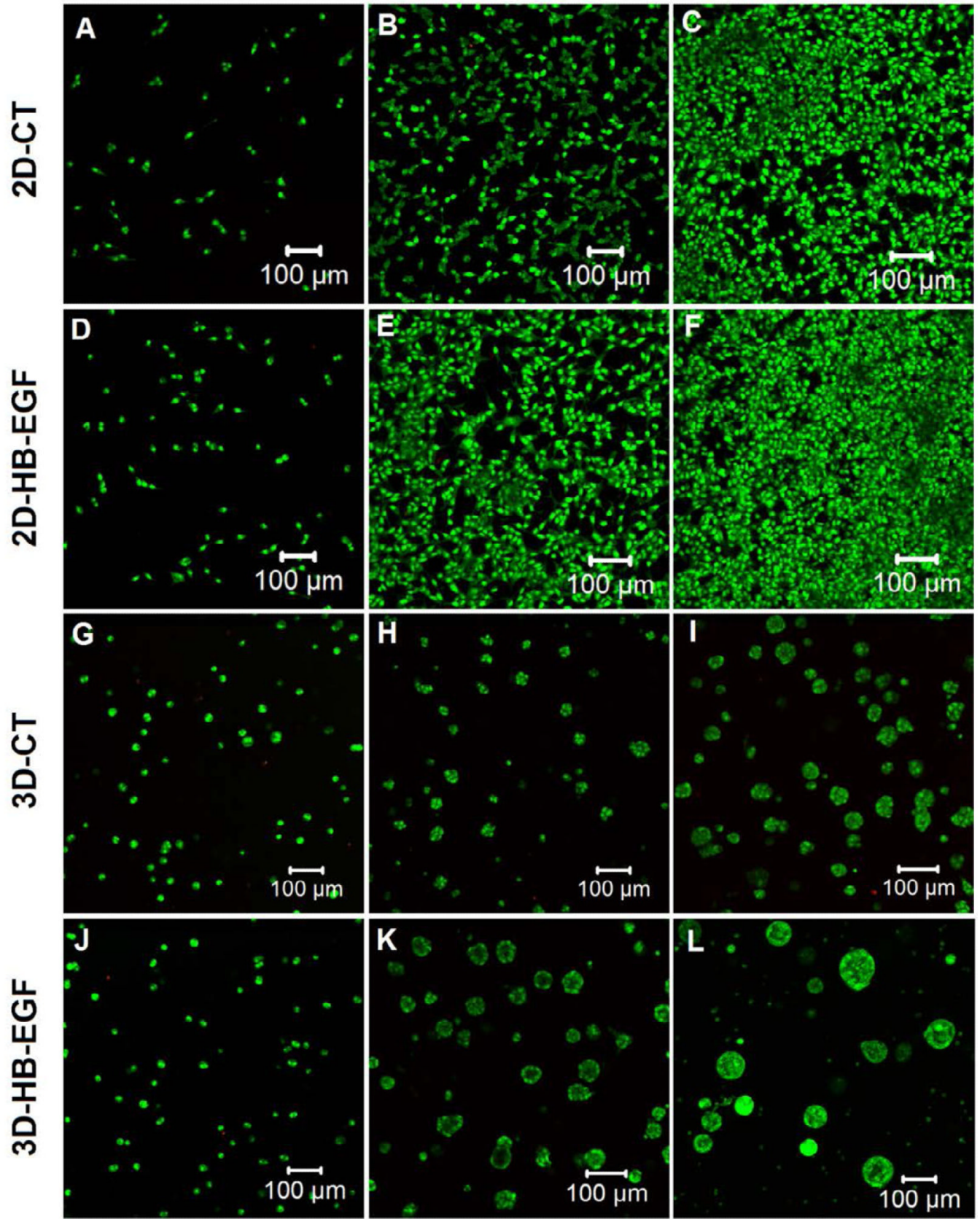

Figure 5.

Representative confocal images of live/dead stained cells cultured under 2D-CT, 2D-HBEGF, 3D-CT and 3D-HB-EGF conditions at day 1, 4 and 7. Live (green) and dead (red) cells were stained with SYTO-13 and propidium iodide, respectively. 


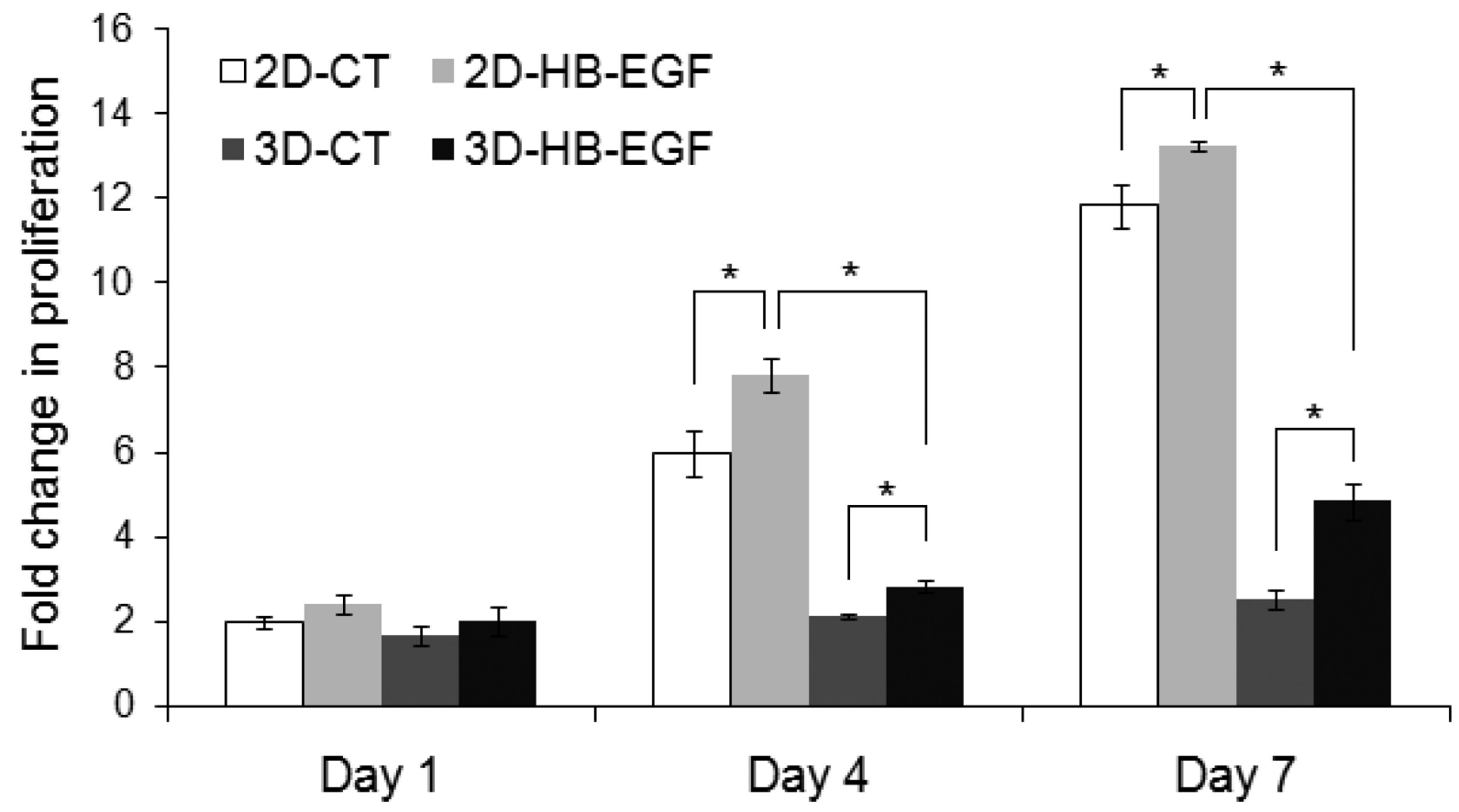

Figure 6.

Proliferation of LNCaP cells cultured on 2D or in 3D with or without HB-EGF as quantified by PicoGreen DNA assay. The fold change in proliferation was calculated by normalizing the cell number at day 1,4 , and 7 to that at day 0 . The initial seeding density was $1 \times 10^{4}$ cells $/ \mathrm{cm}^{2}$ in $2 \mathrm{D}$, and $1 \times 10^{6}$ cells $/ \mathrm{mL}$ in $3 \mathrm{D}$ (*: significant difference, $\mathrm{p}<0.05$ ). 

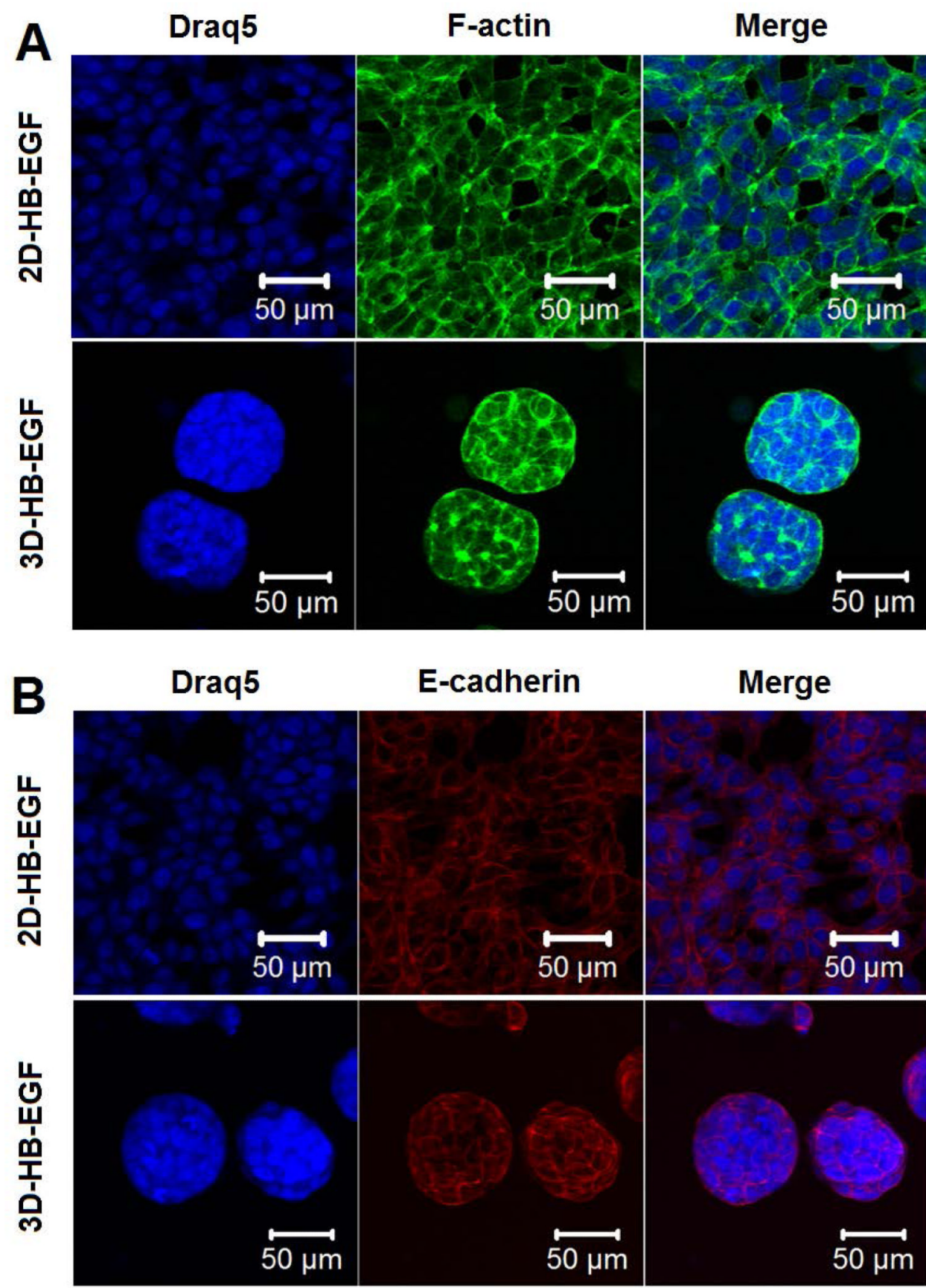

Figure 7.

Confocal images of immunohistochemically stained LNCaP cells after 7 days of culture on 2D (2D-HB-EGF) or in 3D (3D-HB-EGF) in the presence of HB-EGF. Cell nuclei, F-actin and E-cadherin were stained blue, green and red, respectively. 


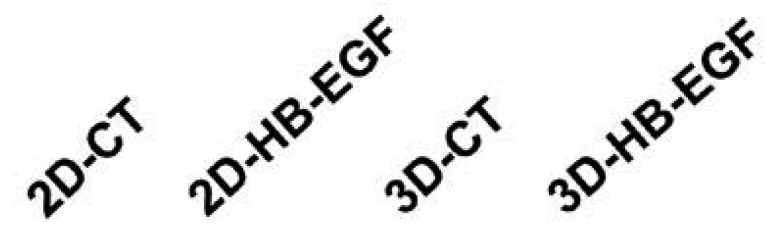

HYAL-1

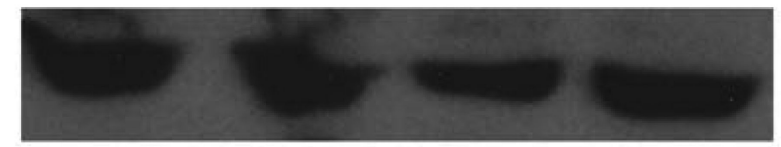

\section{$\beta$-actin}

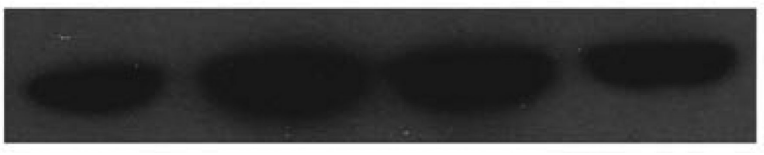

Figure 8.

HYAL-1 expression by LNCaP cells cultured on 2D or in 3D as evaluated by Western blot. $\beta$-actin served as the loading control. 

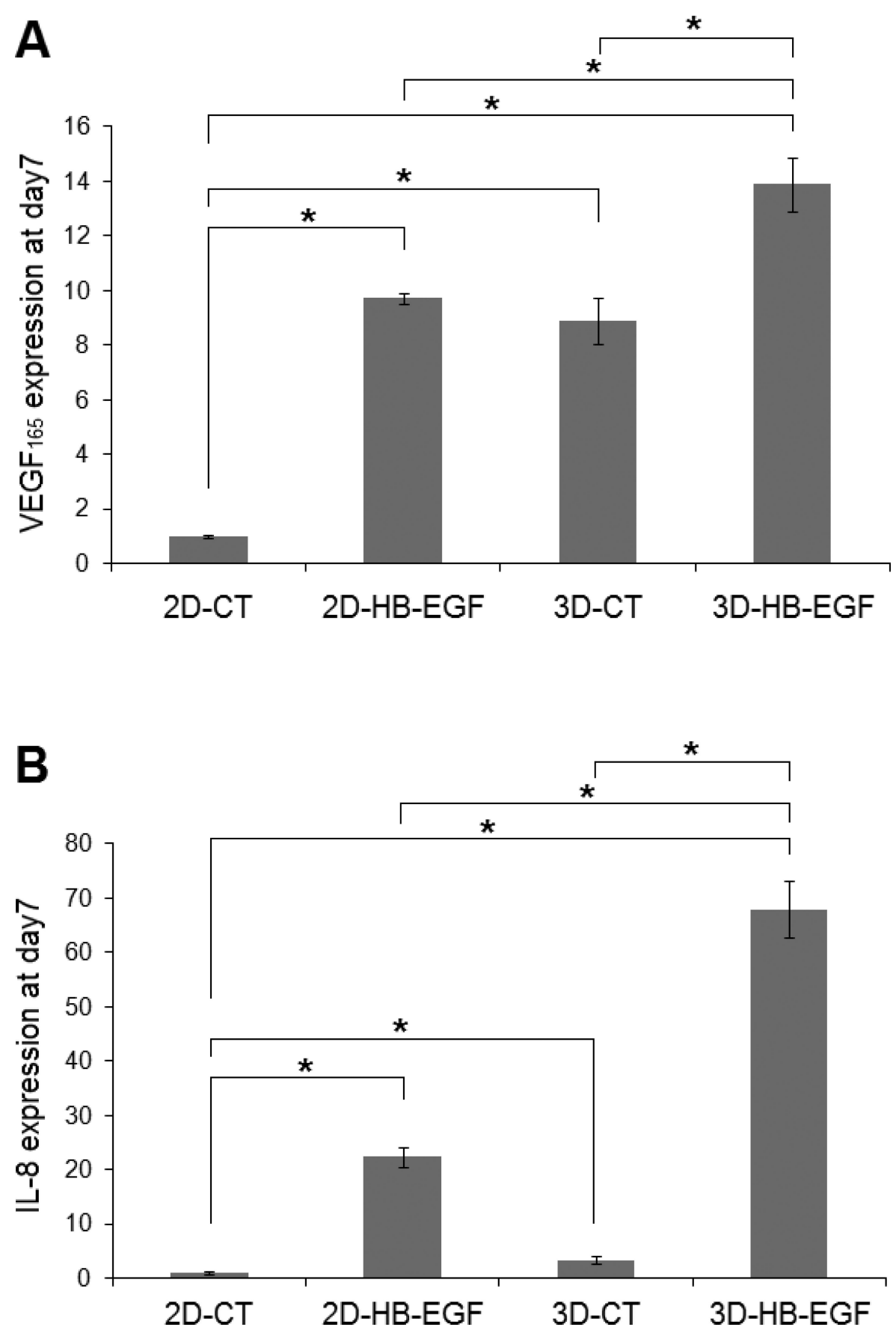

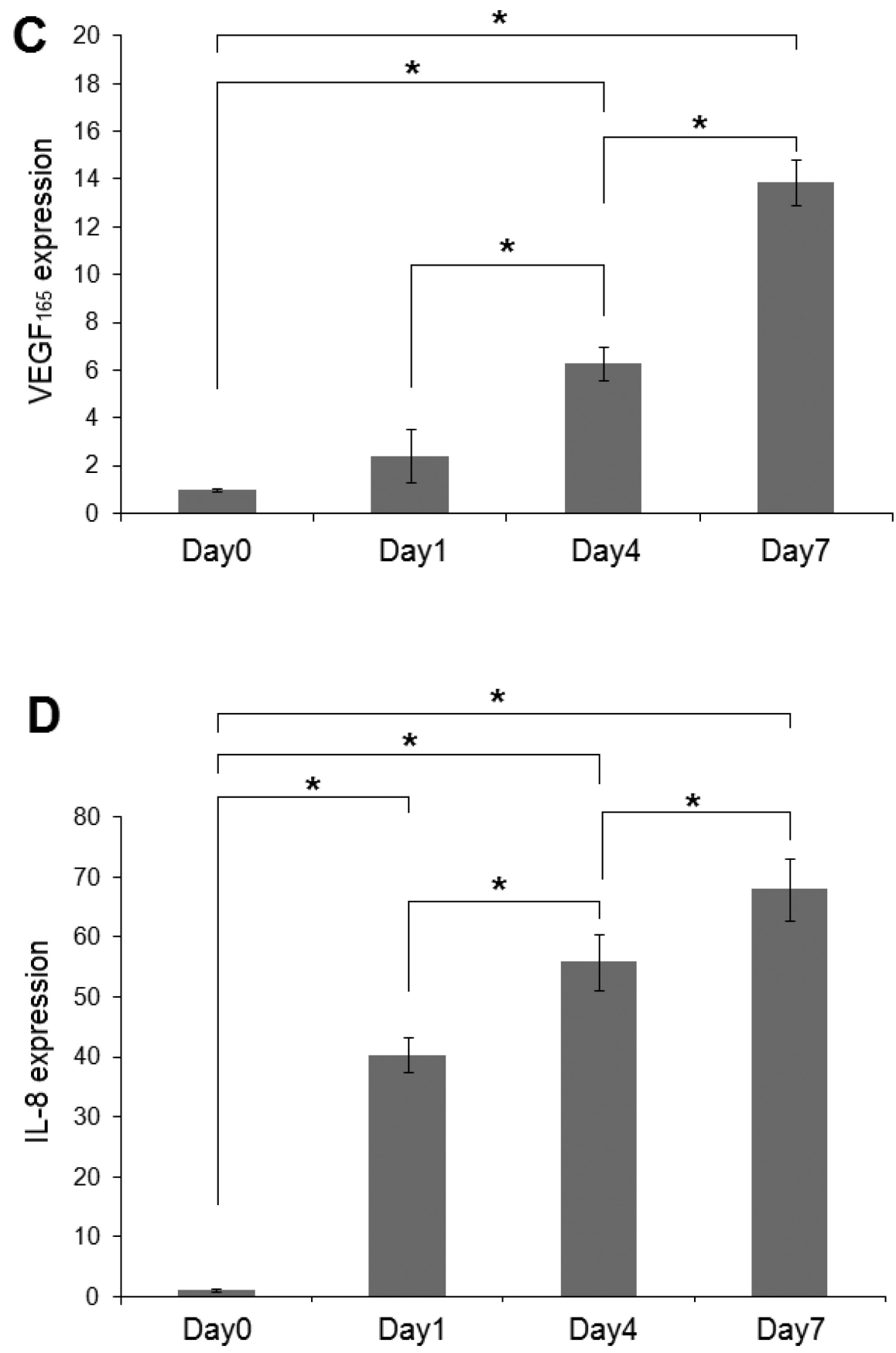

Figure 9.

Quantification by qPCR of the expression at the mRNA level of angiogenic markers by LNCaP cells. (A, B): VEGF (A) and IL-8 (B) gene expression at day 7. Gene expression was normalized to that of 2D-CT at day 7. (C, D): Upregulation of VEGF (C) and IL-8 (D) over 7 days of culture in 3D-HB-EGF system. Gene expression was normalized to the level at day $0 . \beta$-actin served as the normalization control in all qPCR analysis. (*, significant difference, $\mathrm{p}<0.05$ ) 

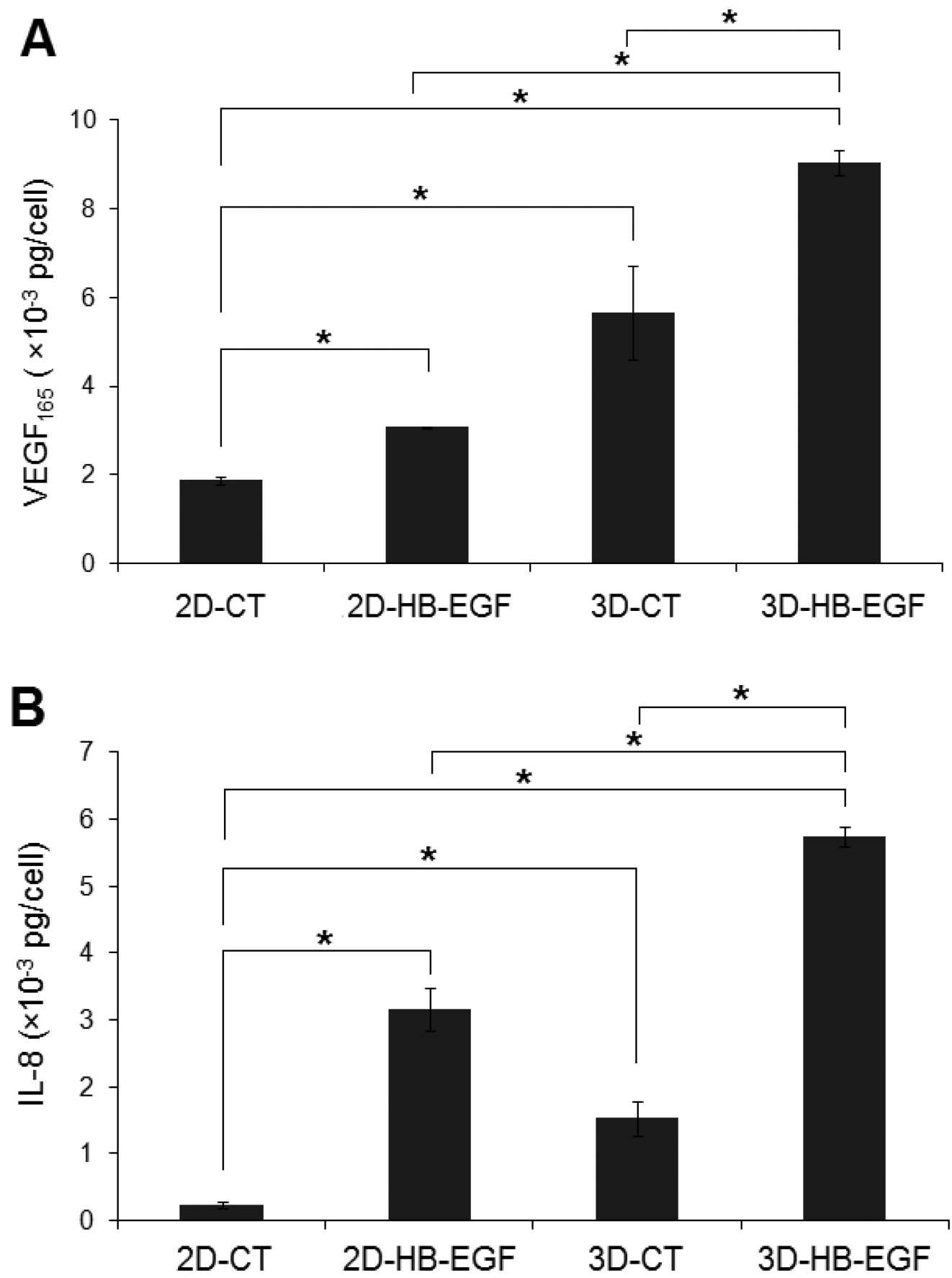

Figure 10.

Quantification by ELISA of the expression at the protein level of angiogenic markers. The amount of VEGF (A) and IL-8 (B) secreted under various conditions was quantified by ELISA after 7 days of culture. Results were normalized to the respective cell number at day 7 for each culture condition as measured by PicoGreen assay. (*: significant difference, $\mathrm{p}<0.05$ ). 